Behind the makeup: The effects of cosmetics on women's self-objectification, and their objectification by others

Dax J. Kellie ${ }^{1, *}$, Khandis R. Blake ${ }^{1,2}$, Robert C. Brooks ${ }^{1,}$

${ }^{1}$ Evolution \& Ecology Research Centre, University of New South Wales Sydney, 2052, Australia

${ }^{2}$ Melbourne School of Psychological Sciences, University of Melbourne, 3011, Australia

Author Note

*Address correspondence to Dax Kellie (d.kellie@unsw.edu.au) 


\begin{abstract}
Does wearing makeup benefit women by changing how they perceive themselves, and are the perceptions that others make of makeup wearers positive, or negative? In two pre-registered experiments, we investigated the effects of makeup on women's self-perceived traits, and others' objectifying perceptions of them. In Experiment 1, 229 women imagined one of four scenarios (e.g., a romantic date). Half applied makeup for that scenario before rating their self-perceived agency, humanness, romantic competitiveness towards other women and reactions to partner jealousy. Results showed little evidence that applying makeup affected women's self-perceived traits. In Experiment 2, 844 participants rated images of women's faces from Experiment 1 on their mental capacity and moral status. Women wearing more makeup were attributed less mental capacity and moral status, with attributions mediated by perceptions that heavier makeupwearers have more sex and are more physically attractive. Findings suggest that although women experience cultural pressure to wear makeup, negative stereotypes of makeup-wearers may lead to detrimental perceptions of women.
\end{abstract}

Keywords: Cosmetics, Self-perception, Objectification, Dehumanization 
Makeup is a regular part of many women's daily grooming routines. A survey of 1,039 respondents within the USA found that more than 70\% apply makeup at least once per week (Statista, 2017), a frequency comparable to European and Asian populations (Biesterbos et al., 2013; Park et al., 2018). Globally, the cosmetic products market is continually growing, valued at \$532 billion in 2017 (Zion Market Research, 2018), with popular beauty brands reporting billions of dollars in sales each year (L'Oreal Annual Report, 2018). Increasing ease and accessibility across social media platforms allows millions of people to follow the latest makeup and fashion trends (Statista, 2019a; 2019b), with fashion and beauty icons like Kylie Jenner reaching as many as 185 million followers (14 July, 2020). Worldwide, a large proportion of women use, purchase and stay up-to-date with makeup.

One reason for makeup's popularity is because it elevates the wearer's perceived attractiveness and femininity (Batres et al., 2018; Borau \& Bonnefon, 2019; Cash et al., 1989; Etcoff et al., 2011; Jones et al., 2015; Jones \& Kramer, 2016; Law Smith et al., 2006; Mileva et al., 2016). As a result, women using makeup may accrue benefits associated with appearing more attractive (Dion et al., 1972), such as more positive impressions of their social and personality traits, or improved earnings (Agthe et al., 2016; Dion et al., 1972; Jackson et al., 1995; Nash et al., 2006; Smith et al., 2009; Putz et al., 2018; Maestripieri et al., 2017). Women who feel more attractive may also experience higher self-esteem, greater well-being (Diener et al., 1995; Goodwin et al., 2012; Penke \& Denissen, 2008), and increased success at attracting romantic partners (see Hill et al., 2012; also see Mileva et al., 2011). Makeup wearers may therefore experience positive effects from wearing makeup.

Stereotypes of women who wear more makeup are not, however, universally positive. Multiple studies find that, compared to women with less makeup or no makeup, women who wear more makeup are more likely to be perceived as sexually available (Osborn, 1996; Mileva et al., 2016; Batres et al., 2018). Thus, women who choose to use makeup for its benefits may also unintentionally lead others to make stereotypical inferences about their sexual activity, a quality for which women are judged more negatively than men (Crawford \& Popp, 2003; Reiss, 1967). Women inferred to be more sexually active may subsequently become objectified (Blake et al., 2016; Kellie et al., 2019; see Bernard et al., 2019, 2020), or valued based on their physical attributes or body parts instead of being valued as a person with full personhood and subjectivity (Fredrickson \& Roberts, 1997). Being objectified negatively impacts how a woman is perceived 
by others (Loughnan et al., 2013; Holland \& Haslam, 2016) and can diminish how she perceives herself (Chen et al., 2013; Holland et al., 2017), increasing the possibility of physical and psychological damage (Calogero \& Pina, 2011; Loughnan et al., 2017; Moradi \& Huang, 2008). Despite these negative consequences, feeling physically or sexually valued - a perception that is considered fundamental to objectification-was recently shown to increase women's self-esteem when it was their romantic partner, and not a male stranger, who physically or sexually valued them (Meltzer, 2019). This finding highlights the contextual limits of objectification theory and suggests that a deeper understanding of how context influences perceptions may provide insight into how women's appearance decisions, including wearing makeup, affect their daily social interactions.

The goal of the current research is to test experimentally the effects, positive and/or negative, of makeup application on women. We do so in order to assess the consequences and benefits of appearances that increase physical valuation. Here we use two experiments to investigate the effects of makeup on (a) women's self-perceived traits, and (b) others' perceptions of women wearing makeup.

\section{Positive effects of makeup}

Women's ability to use makeup to hide or enhance particular facial features may promote positive outcomes in a number of scenarios (Korichi et al. 2008). In professional contexts, makeup may be used to positively impact women's perceived leadership ability when applying for jobs and create favourable impressions in the workplace (Klatt et al., 2016; von Baeyer et al., 1981; also see Netchaeva \& Rees, 2016). Wearing more makeup may also increase perceptions of a woman's competence and warmth (Etcoff et al., 2011) and allow women to manage their social interactions and subjective well-being (Diener et al., 1995; Regan, 2011). However, other research suggests that heavier makeup, compared to little or no makeup, may negatively affect women's perceived leadership and resume evaluations (Cox \& Glick, 1986; James et al., 2018). Still, women may find wearing some amount of makeup beneficial in professional settings.

Makeup may also be useful in romantic contexts. By increasing women's perceived dominance and prestige, makeup may allow romantically motivated women to attract a wider variety of potential romantic partners (Mafra et al., 2020; Mileva et al., 2016) and encourage confidence to test the dating market, even at the expense of a current relationship besieged by a 
jealous partner (Fugère et al., 2015). The effectiveness of makeup in romantic attraction may be especially relevant when high-quality male partners are in demand and competition among women is high (Blake \& Brooks, 2019a; Blake et al., 2018; Hill et al., 2012; also see Netchaeva $\&$ Rees, 2016). Thus, when attracting and competing for high-quality romantic partners, selfsexualizing strategies like wearing makeup can be advantageous for women (see Davis \& Arnocky, 2020 for a review).

\section{Makeup, sexualization, and objectification}

Appearing sexualized (e.g., wearing revealing, tightly-fitted attire, or high amounts of makeup) can increase the likelihood that a woman is sexually objectified, or viewed as an instrument to attain sexual goals (sensu Nussbaum, 1999). A woman's sexualized appearance is frequently used by others as a proximate cue of a woman's sexual interests and behaviors, even though this cue is often inaccurate (Stillman \& Maner, 2009). This is also true of makeup; research shows that women wearing makeup are perceived to be more sexualized (Bernard et al., 2020) and assumed, inaccurately, to be more sexually active than women wearing no makeup (Batres et al., 2018). Women who are sexualized are objectified more strongly than women who appear non-sexualized (Cogoni et al., 2018; Bernard et al., 2018a; Tyler et al., 2017; Vaes et al., 2019), in part due to perceiver associations of sexualized appearances with promiscuity (Blake et al., 2016; Kellie et al. 2019). These assumptions about women's sexual behavior from their appearance may lead some women, including women who wear heavier makeup, to be objectified more than others (see Bernard et al. 2019, 2020).

Objectified women face many potential negative consequences. Objectified women, compared to non-objectified women, activate fewer neural regions associated with empathy within perceivers (Cogoni et al., 2018; Vaes et al., 2019). As a result, being objectified may increase women's vulnerability to verbal, sexual, and physical aggression (Arnocky et al., 2019; Bevens \& Loughnan, 2019; Blake et al., 2016; Davidson et al., 2015; Vasquez et al., 2017). Cultural pressures perpetuate these negative effects by creating an environment where women internalize a view of themselves as objects useful only for their physical appearance (i.e., selfobjectification; Fredrickson \& Roberts, 1997; Calogero \& Jost, 2011). Self-objectification leads to numerous adverse consequences for women's mental health and psychological functioning, including greater body surveillance (Aubrey, 2006; Holland et al., 2017; Sanchez \& Broccoli, 
2008), greater reservation to interact in social situations (Saguy et al., 2010) and lower selfperceived competence, warmth and morality (Loughnan et al., 2017; see Moradi \& Huang, 2008 for a review).

Objectification is one form of dehumanization, a broader classification of perceptions related to the process of viewing another person as less than fully human (see Haslam, 2006). Research finds that sexualized women are dehumanized as well (Bernard et al., 2020; Puvia \& Vaes, 2013; Puvia \& Vaes, 2015; Rudman \& Mescher, 2012; Vaes et al., 2011). Dehumanization involves attributing people less mental capacity, which consists of two dimensions: mental agency, or a person's capacity to think, plan, and act on intentions, and mental experience, or a person's capacity to feel sensations including pain, embarrassment, and desire (Gray et al., 2007). Dehumanization also involves attributing people less moral status, which consists of two comparable dimensions: moral agency, or a person's ability to knowingly commit good or bad actions to another person, and moral patiency, or a person's ability to knowingly receive good or bad actions that are committed to them (Gray \& Wegner, 2009; Gray et al., 2012). These dimensions are suggested to inversely relate: a person who is perceived as an agent is no longer viewed as a patient, and vice versa (Gray et al., 2007; Gray \& Wegner, 2009; Gray et al., 2011; Schroeder et al., 2017). In sexual assault cases, this inverse relationship helps to explain why men and women feel less moral concern for sexualized women but perceive them to be more blameworthy than non-sexualized women (Loughnan et al., 2013). Findings like these suggest there may be multiple forms of female objectification, each resulting in different attributions of mental capacity and moral status (see Morris et al., 2018).

Although it is regularly suggested that men are the primary instigators of objectification towards women (Bareket et al., 2018; Fredrickson \& Roberts, 1997), both men and women are found to objectify women (Blake et al., 2016; Cikara et al., 2011; Fredrickson et al., 1998; Graff, et al., 2012; Gurung \& Chrouser, 2007; Loughnan et al., 2010; Morris et al., 2018; Rudman \& Mescher, 2012; Tyler et al., 2017; Strelan \& Hargreaves, 2005; Vaes et al., 2011). However, the ways in which men and women objectify women, and their reasons for doing so, may differ. Men's objectification of women may relate to sex goals that become salient when men focus on a woman's physical attractiveness (Vaes et al., 2011; Morris et al., 2018). Alternatively, women's objectification of women may relate more closely to a belief that women who self-sexualize are active in the mating market, competitively motivated, and sexually accessible (see Delpriore et 
al., 2018; Muggleton et al., 2018). Some women may feel their potential pool of high-quality male partners is threatened by these sexualized romantic competitors and may subsequently objectify these women as a negative response to this threat (see Delpriore et al., 2018), especially women who perceive themselves as less desirable partners, prefer long-term sexual relationships, or hold conservative sexual values (see Agthe et al., 2011; 2016; Weeden et al., 2008; Weeden \& Kurzban, 2013). Understanding why men and women objectify women is crucial for a broader understanding of what motivates sexism and oppressive behavior.

\section{Context and variation in the effects of sexualisation on women's objectification}

Despite the negative consequences of objectification, under certain circumstances women who draw attention to their physical attractiveness by self-sexualizing may experience positive psychological effects from feeling physically valued. Although women feel more objectified and suffer lower self-esteem when a male stranger values them for their sexuality and physical appearance, contrary to objectification theory (Fredrickson \& Roberts, 1997), women feel less objectified and have greater self-esteem when their long-term romantic partner values them for their sexuality and physical appearance (Meltzer, 2019). Likewise, women who are experimentally instructed to enhance their attractiveness using their own clothes and makeup report higher assertiveness and positive mood (Blake et al., 2020). Even within larger social contexts, women who choose to self-sexualize may feel pleasure, liberation and empowerment from appearing more sexually attractive (Choi \& DeLong, 2019). These findings suggest that feeling physically and sexually valued for their appearance may confer positive effects upon women within interpersonal relationships (Leary \& Baumeister, 2000), some of which may even offset consequences of feeling objectified, such as lower self-esteem (Meltzer, 2019).

It remains unclear to what extent certain scenarios alter the amount of makeup women choose to apply compared to others and, consequently, their self-perceptions. The style and degree of makeup women choose to apply may differ depending on how attractive or competitive they already feel, who they anticipate they will interact with, and the context under which that interaction will occur (Cash et al., 1985; Wagstaff, 2018). In contexts when it is desired, selfsexualizing, including wearing makeup, can benefit a woman's self-perceptions in ways that may offset other negative effects of objectification (Meltzer, 2019; see Choi \& DeLong, 2019), encourage favorable impressions (Etcoff et al., 2011; Klatt et al., 2016; Netchaeva \& Rees, 2016; 
von Baeyer et al., 1981) and help attract romantic partners (Mafra et al., 2020; Mileva et al., 2016; Hill et al., 2012). In other contexts, wearing too much makeup can be more costly for women and lead to negative evaluations (Cox \& Glick, 1986; Delpriore et al., 2018). Knowing whether women's choice to apply or alter their makeup positively influences their selfperceptions of traits can increase our understanding of why women choose to do so, and how this helps to navigate their daily social interactions.

\section{The current research}

Recent research has investigated the relationship between makeup, sexualization and objectification. One study identified that there are subtle differences in how people recognize and cognitively process faces with and without makeup (Bernard et al., 2019). Another study found that women wearing heavy makeup are dehumanized more than women without makeup due to an association of makeup with sexualization (Bernard et al., 2020). The current study expands on these previous findings by using a broader sample of makeup types to investigate whether dehumanizing perceptions of makeup-wearers are due to stereotypical judgements of sexualized women's attractiveness, sexual behaviour, or both. The current study also investigates the possible benefits that women experience by applying makeup under different circumstances (see Batres et al., 2019). Results of our research contribute to discussion of how women's appearance, and their agentic decisions about how they wish to appear, shapes their social interactions.

We conducted two pre-registered experiments designed to test the effects of makeup on women's self-perceptions (Experiment 1), and on other men's and women's attributions of mental capacity and moral status to women depending on the makeup they wear (Experiment 2). Experiment 1 allocated participants to one of four hypothetical scenarios chosen to represent differing contexts for applying makeup: a romantic date, a job interview, an Instagram Post or a control condition. Half of the participants then applied makeup for their scenario, whereas the other half completed a writing task about their scenario, allowing us to separate effects of contemplating the scenario from the effects of applying makeup for the scenario. As previous research finds that self-applied cosmetics and professionally-applied cosmetics differ in their effects on women's attractiveness (Jones \& Kramer, 2016), to standardize the skill-level of makeup application across women we elected to have participants apply makeup digitally using MakeupPlus (http://makeup.meitu.com/en/), a phone and iPad app which uses facial feature 
recognition to allow realistic makeup application to a photo. We tested whether applying makeup, and the amount of makeup applied, affected women's self-perceptions of traits associated with their mental capacity, moral status, romantic competitiveness towards other women, and reactions to partner jealousy.

In Experiment 2, to test for an association between makeup and objectification, male and female participants rated the amount of makeup they perceived women from Experiment 1 to wear and how much mental capacity and moral status they attributed to those women. To better understand the sources of variation in men's and women's objectifying perceptions, Experiment 2 also tested whether effects of makeup on objectifying perceptions were mediated by a woman's perceived attractiveness or her perceived likeliness to have casual sex. Highly controlled experiments that utilize strongly regulated stimuli or experimental designs to minimize unwanted variation - although important for testing causal inferences (Berkowitz \& Donnerstein, 1982) may unintentionally measure artificial or unrealistic behaviors that unreliably represent behaviors in variable, and often messy, real-world contexts (Eastwick et al., 2013; Mitchell, 2012; see Davis et al., 2014 for a discussion in sexual aggression research). However, longer surveys that allow participants to rate a wider range of stimuli can cause mental fatigue, undermining reliability of participant responses (Galesic \& Bosnjak, 2009; Herzog \& Bachman, 1981; Hopstaken et al., 2015; Lavrakas, 2008). Thus, we opted to measure participants' judgments of large numbers of women's faces by asking each participant to rate a randomly selected subset of the total collection of women's faces to increase the scale and ecological validity of our results.

\section{Experiment 1}

\section{Method}

\section{Experimental design}

Our first experiment investigated whether makeup application increases women's selfperceived agency, humanness, competitiveness and resistance to a partner's jealousy using a 4 (scenario prime: romantic date, job interview, Instagram Post, control) $\times 2$ (makeup application condition: makeup, non-makeup) factorial experimental design. Under the supervision of one investigator ([MASKED]), participants completed an online questionnaire where they were allocated at random to one of the eight treatment combinations. After completing the makeup task or the non-makeup writing task, all participants proceeded to complete measures of explicit 
agency, humanness, competitiveness, resistance to a partner's jealousy and implicit agency (in that order). To control for effects of self-perceived attractiveness and preferences for long- or short-term sexual relationships on women's feelings of competitiveness, self-perceived mate value and sociosexual orientation were included as covariates.

All pre-registered predictions, materials, and methods for Experiment 1 are available at the Open Science Framework (https://osf.io/xp9qc/?view_only=4bd752bf1c28478bb4ff866f4b468c71).

\section{Predictions}

We predicted that women who applied makeup would have higher self-perceived agency and humanness (due to more positive physical valuation), less positively evaluate other women (due to higher intrasexual competitiveness) and be more willing to behave resistantly to a partner's jealousy (due to increased confidence to test the mating market) than women who did not apply makeup (H1). We also predicted that among those who did apply makeup, applying more makeup would have a stronger positive effect on women's self-perceived traits than applying less makeup (H2). Our third prediction was that women would choose to apply more makeup for experimental scenarios (a romantic date, a job interview, an Instagram Post) compared to our control scenario (the grocery store), with the highest amount of makeup applied for a hypothetical romantic date (makeup as mate attraction) or an Instagram Post (makeup as same-sex competition) (H3). We hypothesized these effects because physical attractiveness is particularly valuable for women when attracting male partners and competing with other women.

\section{Participants}

Power analysis using GPower 3.1 suggested that a sample of 191 participants would provide power at .80 to detect small to medium effects (Cohen's $d=0.25$ ). Anticipating $\sim 25 \%$ of data loss due to participants not meeting exclusion criteria, a sample of 250 women participants ranging from 18 to 59 years $\left(M_{\mathrm{age}}=22.1, \mathrm{SD}_{\mathrm{age}}=4.2\right)$ were recruited to participate in a survey on makeup and first impressions using an online recruitment system at an [MASKED] university. Of this 250 sample, 11 participants were excluded from analysis for not following experiment instructions, leaving a final total of 239 participants. Ethics approval for Experiment 1 and Experiment 2 was granted by [MASKED] human ethics committee (HC180116). All participants provided their consent before completing the study and were paid [MASKED] as compensation for participating in a 30-minute survey [MASKED]. Participants ranged in ethnicity, with the 
majority of women identifying as South East Asian (38.9\%), Chinese Asian (37.6\%) or North Western European, British or Irish (9.2\%; see supplementary material for full list of ethnicities). The majority of participants were single $(67.2 \%)$ or in a monogamous relationship (29.3\%), with the remaining $3.4 \%$ of participants in an open relationship.

\section{Procedure}

\section{Scenario priming conditions}

Participants answered three priming questions about their assigned scenario (see Supplementary Material), then were provided instructions about the scenario. In the romantic date scenario, participants were asked to think of a person they were attracted to as a partner, either someone famous or someone they knew. If participants were in the makeup condition, they were instructed to apply makeup in the way they wished to appear for an imaginary date with this person. If in the non-makeup writing condition, participants read the same scenario, but were instructed to write about preparing for an imaginary date with this person. In the job interview scenario, participants were instructed to imagine today was the day of a job interview and to apply makeup in the way they wished to appear (or to write about preparing for their interview in the non-makeup writing condition). In the Instagram post scenario, participants were asked to imagine they were about to make a media post about themselves on Instagram (or an equivalent social media account if they didn't use Instagram) and to apply makeup in the way they wished to appear in their post (or to write about how they wished to appear for their post in the nonmakeup writing condition). Whether the romantic date, job interviewer or Instagram followers were men or women was not specifically identified. In the control scenario, participants were told to imagine they were about to go to the grocery store and to apply makeup in the way they wished to appear at the store (or write about their grocery store routine in the non-makeup writing condition). The control scenario was chosen as a routine event where women were still exposed to the public and may wish to prepare for the event, but that we anticipated would not stimulate any specific agentic, competitive or emotional reactions.

To ensure participants took time to consider and apply their desired amount of makeup (or write sufficient prose) for their allocated scenario, participants were informed that they were allocated 5 minutes minimum to apply their makeup, or that they must write 200 words minimum, but that they could take as much time as they required until they were satisfied with their effort. Participants in the makeup condition were unable to continue the survey until the 
allocated 5 minutes had elapsed, and in the non-makeup writing condition until they wrote 200 words. The amount of time participants spent applying makeup or writing ranged from 5 to 30 minutes, though fewer than 5 per cent spent longer than 10 minutes on their task.

\section{Makeup condition}

To apply makeup using the app, participants in the makeup condition had their photograph taken by the supervising researcher (DK) using a Logitech ${ }^{\mathrm{TM}}$ webcam in laboratory conditions. Participants were not asked to remove makeup that they may have already been wearing prior to the photograph as this would have added an extra step to the experimental treatment for some participants and not for others. Photographs were taken in the same room under identical lighting conditions, including additional lighting directed at a 10-degree angle to the right of participants to reduce shadows. Participants were instructed to hold a neutral expression and stare directly into the camera. After the photograph was successfully taken, the researcher transferred the photo of the participant to a $1^{\text {st }}$ generation $\mathrm{iPad}$ mini (iOS version 9.3.5) and loaded the photograph into the MakeupPlus app (version 5.0.0).

MakeupPlus is a free digital makeup application app that uses facial feature recognition to allow users to apply various types of cosmetics to their faces. Makeup effects that could be applied by participants included lipstick, eyeliner, foundation, blush, eyelashes, mascara, and contouring. Participants could adjust the intensity or subtlety of each makeup effect using onscreen effect sliders. To ensure that participants only used makeup to alter their appearance, participants were not allowed to use automatic themes, beautify effects (an automatic skinsmoother), contact lenses, or decorations (e.g., tattoos, bowties, etc.). Participants were also not allowed to use fine-adjustment effects (i.e., altering automatic facial mapping) so that facial recognition mapping remained standardized across participants.

When participants finished applying makeup to their photo, the makeup-applied photo was transferred from the iPad back to the computer by the researcher so that the photo and scenario could be visible to the participant. The makeup-applied photo was positioned to occupy the entire right side of the computer screen, along with the phrase "This is the makeup you have chosen to wear for a [allocated scenario]" displayed in the top right corner of the screen. The survey was positioned to occupy the entire left side of the screen. Participants completed the remainder of the questionnaire with their photo and scenario displayed in this way. 


\section{Non-makeup writing condition}

In the non-makeup writing condition, after completing the priming questions participants, instead of applying makeup participants wrote 200 words (or more) about their preparation for, and desired outcome of, the allocated scenario into an open-answer panel of their online survey. Participants then completed the remainder of the questionnaire.

\section{Measures}

\section{Amount of Makeup Applied}

The amount of makeup participants applied was estimated using ratings gathered from an independent sample of participants who viewed the photographs as part of Experiment 2. Each before and after photograph of Experiment 1 participants was rated by between 77 and 88 participants of Experiment 2 for the following scale: "How much makeup do you think this person is wearing?" $(0=$ No makeup, $7=\mathrm{A}$ lot of makeup; $M=3.35, S D=1.73)$. The average rating of each woman's face before applying makeup was subtracted from the same woman's average rating after applying makeup to provide an estimate of the amount of makeup each participant applied.

\section{Explicit agency}

Agency was measured explicitly using a 16-item measure from Blake and colleagues (2016). Participants indicated to what extent each of 16 words described how they felt about themselves at the present moment. Eight words were associated with high agency (decisive, driven, a go-getter, self-aware, persistent, independent, productive, strong-minded) and eight words were associated with low agency (dependent, meek, hesitant, apathetic, idle, inactive, unconcerned, scatter-brained). Low agency items were reverse-coded. All items were assessed using a 7-point Likert scale ( $1=$ Not at all, $7=$ Extremely). Items were averaged to create an overall explicit agency score for each participant $(\alpha=.81)$.

\section{Humanness}

Humanness was measured using the Humanness Scale (Bastian et al., 2012). This 20item measure asks participants to rate how much they feel each word describes them using a 7point scale (-3 = Not at all; 3 = Very much so). Examples of words include "broadminded", "polite", “curious", "fun-loving”, "rude”, “impatient”, “jealous” and "shy”. Participants were also presented with 10 additional unrelated words (e.g., "bubbly", "witty”). Word order was 
randomized. Separating scores into two dimensions, following methods by Haslam et al. (2005) and Bastian et al. (2012), returned low internal measure reliability for each separate dimension (Human Uniqueness: $\alpha=.65$; Human Nature: $\alpha=.58$ ). Thus, all 20 items were combined to create an overall average humanness score for each participant $(\alpha=.75)$.

\section{Competitiveness towards other women}

Competitiveness towards same-sex individuals was measured using an adapted version of the individual differences in intrasexual competition scale (ICS) developed by Buunk \& Fischer (2009). This measure has been used by more than 30 studies to indicate competition amongst romantic competitors (e.g., Arnocky et al., 2019; Blake \& Brooks, 2019; Borau \& Bonnefon, 2019b; Watkins et al., 2012). The scale measures positivity and negativity toward unknown same-sex individuals of reproductive age, usually among women. Given that derogation is a popular tactic for female-female competition, women who rate other women more negatively are seen as more intrasexually competitive (Buunk \& Fischer, 2009). For this reason, we used the ICS to measure intrasexual competition, with negative scores indicating higher intrasexual competitiveness, and positive scores indicating lower intrasexual competitiveness. Participants viewed images of two women's faces, one at a time, and judged their attractiveness ("How attractive do you think this person is?"), interpersonal traits ("How intelligent do you think this person is?", "How warm do you think this person is?", "How competent do you think this person is?") and their desire to interact with her ("How likely would you be to hire this person as a colleague?", "How likely would you be to be friends with this person?"). All items were assessed using a 7-point Likert scale ( $1=$ Not at all, $7=$ Very). Items for both women were averaged to create one overall score $(\alpha=.90)$. All participants viewed the same two women's faces, randomly selected from an open-access collection of neutral front-faced faces (https://doi.org/10.6084/m9.figshare.5047666.v3).

\section{Resistance to a partner's jealousy}

A short 6-item measure assessed to what extent women anticipated using various behaviors to avoid or undermine a male partner's jealousy tactics, indirectly assessing each woman's willingness to test the mating market at the expense of an ongoing relationship. The 6 items were borrowed from a longer 12-item measure by Buunk and Fisher (2009). Participants were asked to rate which behaviors they believed they were most likely to do if their current partner believed that they were interested in other men using a 7-point Likert scale $(1=$ Not at 
all, 7 = Very Likely). Participants not in a current relationship were asked to answer honestly as if they were in a current relationship. Examples include how likely women were to "Tell your boyfriend that you were going to visit family, but really go out with friends", "Not let him put his arm around you in public", and "Fight with him because he wants to spend more time with you than desired." All 6 items were combined to create an average overall resistance to a partner's jealousy score $(\alpha=.79)$.

\section{Implicit Agency}

Implicit agency was measured using an intentional binding task (Haggard et al., 2002; Moore \& Haggard, 2008; Moore \& Obhi 2012; Voss et al., 2010). Intentional binding tasks assess the subjective experience of temporal intervals through voluntary action (Haggard et al., 2002). Although the mechanisms of intentional binding and explicit agency may be partially separable (Ebert \& Wegner, 2010), intentional binding has been shown to reliably link to an individual's sense of agency (Imaizumi \& Tanno, 2019; Voss et al., 2010). In this intentional binding task, participants were informed that they would hear an auditory tone that can be stopped by clicking on a "stop" button on the screen. Participants were also told that there would be a delay between when they clicked the button and when the tone would stop, which would be no longer than 1 second (1000 ms). After the tone had stopped, participants were asked to estimate how long they thought the delay was using a 9-point scale $(1=100$ milliseconds, $9=$ 900 milliseconds). The actual delay between the participant clicking on the "stop" button and the tone stopping for each question was predetermined by random selection prior to the experiment, and was always either $100 \mathrm{~ms}, 400 \mathrm{~ms}$, or $700 \mathrm{~ms}$. Each participant was presented with the same delay times in the same order.

Participants are considered more agentic if they answer that the delay between their voluntary action (clicking the button) and the consequence (the tone stopping) is shorter on average because these individuals connect their voluntary action to the consequence more readily, demonstrating their belief that they are an agent that influences their environment (Haggard et al., 2002; Moore \& Obhi, 2012). Participants completed 5 practice trials and 20 recorded trials. For each recorded trial, we calculated the difference between the actual delay and the participant's selected delay. Differences for all 20 recorded trials were combined to create an average score $(\alpha=.90)$. 


\section{Sociosexuality}

The Revised Sociosexual Orientation Inventory (R-SOI, Penke \& Asendorpf, 2008) is a 9-item measure used to assess participant's attitudes, behaviors and desires for non-committal or casual sex. Items were assessed using a 9-point Likert scale. Examples of items are, "With how many partners have you had sex within the past month?" (0 to 20 or more), "Sex without love is OK" ( 1 = Strongly disagree, 9 = Strongly agree $)$, and "How often do you have fantasies about having sex with someone with whom you do not have a committed romantic relationship?" $(1=$ never, $9=$ at least once a day; $\alpha=.89$ ).

\section{Mate Value}

Mate value was assessed using a 4-item self-report measure (Edlund \& Sagarin, 2014). Participants were asked to rate themselves using a 7-point Likert scale on how desirable they believe they are as a partner. Examples of items are "Overall, how would member of the opposite sex rate your level of desirability as a partner on the following scale?” (1 = Extremely undesirable; 7 = Extremely desirable $)$ and "Overall, how good of a catch are you?" $(1=$ Very bad catch; 7 = Very good catch; $\alpha=.86)$.

\section{Data Analysis}

Following our pre-registered analysis plan, to determine the effects of makeup and scenario on women's self-perceived traits a series of five General Linear Mixed models were used to test each our five dependent variables - explicit agency, implicit agency, humanness, competitiveness and resistance to a partner's jealousy. Each model included makeup condition, scenario, amount of makeup applied, and interaction effects of makeup condition $\times$ scenario and scenario $\times$ amount of makeup applied. Participant SOI and mate value were included as covariates in each model. Our measure of resistance to a partner's jealousy was analyzed using a negative binomial regression to account for positively skewed residuals.

\section{Results and Discussion}

Neither makeup condition, scenario, nor amount of makeup applied had significant effects on any of our dependent variables (Table 2; see Table 1 for average ratings). A marginally significant effect of scenario on implicit agency (Table 2), however, suggested that regardless of makeup, women may feel less agentic in scenarios like posting to social media and job 
interviews than in more mundane scenarios like grocery shopping. We found no significant interaction effects on self-perceived traits (Table 2).

Contrary to our predictions, our results provide little evidence to support that applying makeup alters women's self-perceived agency, humanness, competitiveness or resistance to a partner's jealousy (H1). Self-perceived traits remained unaffected by the amount of makeup a woman applied (H2) or the scenario a woman applied makeup in preparation for (H3). An additional general linear model testing the effects of scenario on the amount of makeup applied, with participant SOI and mate value as covariates, confirmed that the effect of scenario on makeup applied (H3) was non-significant $(p=.437)$. Covariate effects did show that women with higher mate value also had greater self-perceived explicit agency and humanness (Table 2), supporting evidence that greater physical attractiveness is linked with positive self-perception (Diener et al., 1995; Goodwin et al., 2012; Penke \& Denissen, 2008). Women with higher mate value were also more likely to behave resistantly to a jealous partner (Table 2), and women with higher sociosexuality less positively evaluated same-sex individuals than women with low sociosexuality (Table 2). It is possible these resistant behaviors and negative evaluations were motivated by feelings of competitiveness towards same-sex individuals (Buss \& Schmitt, 1993; Fugère et al., 2015), but without knowing the sexual orientation of our participants and due to the correlational nature of our covariates, our conclusions remain speculative. Overall, findings from Experiment 1 suggest that applying makeup and viewing oneself wearing makeup does not affect women's self-perceptions.

Provided the large proportion of participants in a monogamous or open relationship within our sample (32\%, 75 women), we conducted additional exploratory analyses to test whether relationship status had an effect on our dependent variables. We added relationship status, dummy coded as "single" or "in a relationship", as an additional main effect within each of our original regression models, as well as all interaction effects between relationship status, makeup condition, scenario, and makeup applied. We found a significant interaction effect between relationship status and the amount of makeup applied on women's competitiveness towards other women $\left(F_{1}=4.07, p=.045\right)$ because single women who applied more makeup evaluated other women slightly more negatively $(b=.11, S E=.40)$, whereas women in a relationship who applied more makeup evaluated women more positively $(b=-.45, \mathrm{SE}=.60)$. 
Neither slope differed significantly from zero. No other significant effects of relationship status on self-perceived traits were present (see supplementary material for full results). 
Table 1. Average ratings of women's self-perceived traits and zero-order Pearson's correlation coefficients.

\begin{tabular}{llccccccc}
\hline$\#$ & Variable & $M$ & $S D$ & 1 & 2 & 3 & 4 & 5 \\
\hline 1 & Explicit Agency & 4.67 & 0.74 & 1.00 & & & & \\
2 & Implicit Agency & -21.34 & 120.23 & -.01 & 1.00 & & & \\
3 & Humanness & 0.81 & 0.57 & $.51^{* * *}$ & -.01 & 1.00 & & \\
4 & Competitiveness & 4.64 & 0.89 & -.02 & .08 & .09 & 1.00 & \\
5 & Resistance to a partner's & 2.53 & 1.16 & -.09 & $.14^{*}$ & $-.16^{*}$ & $-.15^{*}$ & 1.00 \\
& jealousy & & & & & & & \\
\hline
\end{tabular}

Note: Explicit agency, competitiveness and resistance to a partner's jealousy were measured using a 7-point Likert scale ( $0=$ Low, $7=$ High). Humanness was measured using a 7-point Likert scale (-3 = Low, 3 = High). Negative implicit agency score represents greater agency, with values further from zero indicating more extreme values. ${ }^{* * *} p<.001,{ }^{* *} p<.01,{ }^{*} p<.05,{ }^{\dagger} p$ $<.10$. 
Table 2. Results from general linear models of effects of makeup, scenario, amount of makeup applied and their interactions on women's explicit agency, implicit agency, humanness, competitiveness towards other women and resistance to a partner's jealousy. Participant sociosexual orientation (SOI) and mate value are included as covariates.

\begin{tabular}{|c|c|c|c|c|c|c|c|c|c|c|c|c|c|c|c|}
\hline & \multicolumn{3}{|c|}{ Explicit Agency } & \multicolumn{4}{|c|}{ Implicit Agency } & \multicolumn{2}{|c|}{ Humanness } & \multicolumn{3}{|c|}{$\begin{array}{c}\text { Competitiveness } \\
\text { towards other } \\
\text { women }\end{array}$} & \multicolumn{3}{|c|}{$\begin{array}{c}\text { Resistance to a } \\
\text { partner's jealousy }\end{array}$} \\
\hline & d.f. & $F$ & $p$ & d.f. & $F$ & $p$ & d.f. & $F$ & $p$ & d.f. & $F$ & $p$ & d.f. & $F$ & $p$ \\
\hline Makeup & 1 & 0.10 & .757 & 1 & 0.08 & .777 & 1 & 0.18 & .675 & 1 & 0.19 & .660 & 1 & 1.28 & .260 \\
\hline Scenario & 3 & 0.650 & .584 & 3 & 2.50 & $.061^{\dagger}$ & 3 & 0.33 & .800 & 3 & 0.05 & .986 & 3 & 0.26 & .854 \\
\hline Amount of Makeup & 1 & 0.73 & .394 & 1 & 0.02 & .895 & 1 & 0.21 & .645 & 1 & 0.25 & .612 & 1 & 0.34 & .559 \\
\hline \multicolumn{16}{|l|}{ Applied } \\
\hline Makeup $\times$ Scenario & 3 & 0.93 & .926 & 3 & 0.64 & .640 & 3 & 0.84 & .473 & 3 & 0.32 & .810 & 3 & 0.40 & .753 \\
\hline $\begin{array}{l}\text { Scenario } \times \text { Amount } \\
\text { of Makeup Applied }\end{array}$ & 3 & 0.88 & .879 & 3 & 0.78 & .779 & 3 & 0.08 & .973 & 3 & 1.03 & .381 & 3 & 0.69 & .560 \\
\hline \multicolumn{16}{|l|}{ Covariates } \\
\hline SOI & 1 & 1.90 & .170 & 1 & 0.83 & .834 & 1 & 0.55 & .461 & 1 & 5.95 & $.016^{*}$ & 1 & 0.26 & .614 \\
\hline Mate Value & 1 & 9.74 & $.002 * * *$ & 1 & 0.31 & .306 & 1 & 16.87 & $<.001 * * *$ & 1 & 0.01 & .940 & 1 & 7.91 & $.005^{* *}$ \\
\hline
\end{tabular}

Note: Resistance to a partner's jealousy was analyzed using a negative binomial distribution model to account for positive skew of residuals. ${ }^{* * *} p<.001,{ }^{* *} p<.01,{ }^{*} p<.05,{ }^{\dagger} p<.10$. 


\section{Experiment 2}

\section{Method}

\section{Experimental design}

Male and female participants rated a randomly selected subset of images of women's faces from Experiment 1 on how much makeup they perceived each woman was wearing and how much mental capacity and moral status they believed each woman had. Participants also rated women's attractiveness and their likeliness to pursue casual sex.

For each of 101 different women's faces from Experiment 1 in our sample, there were two images rated by participants: a pre-makeup image (i.e., the image of each woman before applying makeup using MakeupPlus) and a makeup-applied image (i.e., the image of each woman after applying makeup). Therefore, a total of 202 possible faces of women were rated. Faces were randomly sorted into 10 groups of women's faces that participants were randomly allocated to rate. Each group consisted of 10 faces of different women (and in two groups, 11 faces), with an equal number of pre-makeup and makeup-applied faces within each group (i.e., 5 pre-makeup faces and 5 makeup-applied faces). To ensure that no two faces were of the same woman within each group, each group had a sister-group consisting of the alternative image of the same 10 (or 11) women (i.e., group 1 contains pre-makeup images of women $a$ and $b$ and makeup-applied images of women $x$ and $y$, whereas group 2 contains pre-makeup images of women $x$ and $y$ and makeup-applied images of women $a$ and $b$ ). To control for variation in dehumanization due to a person's self-perceived desirability or their attitudes towards casual sex, participant's self-perceived mate value and sociosexual orientation were measured as covariates.

All pre-registered predictions, materials, and methods for Experiment 2 are available at the Open Science Framework (https://osf.io/xp9qc/?view only=4bd752bf1c28478bb4ff866f4b468c71).

\section{Predictions}

We predicted that heavier makeup would decrease perceptions of women's mental agency, mental experience, moral agency and moral patiency (H4), following findings that sexualized women can be cognitively and visually processed as objects (Cogoni et al., 2018; Gervais et al., 2013) and perceived to have lower competence, warmth, morality and humanness when focus is placed on their sexualized appearance (Heflick \& Goldenberg, 2009; Heflick et al., 2011; Loughnan et al., 2010). We also predicted that makeup effects on mental and moral 
attribution would be mediated by the target woman's perceived attractiveness and perceived likeliness to pursue casual sex (H5), qualities shown to associate with greater female objectification. As women higher in attractiveness are expected to activate sex-goals in heterosexual men but not heterosexual women, we predicted that perceiving a woman to be more attractive would increase men's objectifying perceptions more than women's (H6). Alternatively, as unrestricted sexual behavior is expected to activate more competitively-motivated negative responses towards same-sex individuals in women but may still activate sex-goals in men, we predicted that perceiving a woman to be more likely to have casual sex would increase both men's and women's objectifying perceptions (H6).

\section{Participants}

Due to participants viewing only a subset of the total number of women's faces, a power analysis using GPower 3.1 determined that a sample of 640 participants were necessary for .8 power to detect medium effects (Cohen's $d=0.4$ ). Anticipating that $\sim 25 \%$ of data would be removed due to a proportion of participants not meeting inclusion criteria (outlined below), a total of 850 participants were recruited on Amazon's Mechanical Turk to complete an online survey. To control the demographic of participants within our survey, participants were only able to complete this survey if they had an approval rating of more than $97 \%$ on Mechanical Turk, resided in the USA and identified a valid current state of residence. Additionally, given that a number of accounts on MTurk are non-human accounts, prior to viewing the Participant Information Statement, participants were only allowed to begin the survey after completing a robot CAPTCHA task and a photo identification task where they identified the emotion depicted by the characters in a photo in an open response answer. Prior to analysis, six participants were removed for not passing an attention check, leaving a final sample of 844 participants (422 men, 422 women) ranging in age from 18 to $70\left(\mathrm{M}_{\mathrm{age}}=34.8, S D=10.9\right)$. All participants provided informed consent before completing the study and paid \$2.00 USD to complete a 15-minute survey (a rate of $\$ 8.00$ per hour).

The majority of participants had completed an undergraduate university degree $(50.5 \%)$, a post graduate degree (17.9\%), received a diploma (16.1\%), or high school $(12.6 \%)$ as their highest level of education, with 3\% reporting they had completed another level of education. Participants were mainly Caucasian/White (70.4\%), with the remaining participants being African American/Black (10.5\%), Hispanic (4.7\%), East Asian (4.5\%), South East Asian (3.4\%), 
Mixed (3.1\%), Native American (1.6\%), Indian/Pakistani/Nepalese (1.1\%), Middle Eastern $(0.5 \%)$ or another unlisted ethnicity $(0.2 \%)$. A small proportion of participants reported being single (5.4\%) compared to those reporting they were in a long-term relationship (36.3\%) or married $(20.2 \%)$, though $37.5 \%$ of participants selected their relationship status as "Other". Participants self-identified themselves as exclusively or mostly attracted to men (40.6\%), exclusively or mostly attracted to women (52.7\%) and attracted equally to both men and women $(5.7 \%)$.

\section{Procedure}

Participants first completed demographic, sociosexuality and mate value measures. Participants were then randomly allocated to view one of 10 groups of faces of women from Experiment 1. Participants viewed each face one-at-a-time in a random order and rated each woman on mental and moral indices, perceived amount of makeup, perceived attractiveness and perceived likeliness to have casual sex. These questions were presented in a random order throughout the entire survey.

\section{Measures}

\section{Indices of mental and moral perceptions}

We asked a series of questions to assess the mental and moral perceptions of women using the same 7-point scale ( $1=$ Not at all; $7=$ Extremely). Mental Agency and Mental Experience of a target woman were each assessed using two items, respectively (from Gray et al, 2007), selected as the items with the highest factor loadings from Blake and colleagues' (2016) shortened agency scale, used to assess perceptions of sexualized compared to non-sexualized women. Mental Agency items were "How capable do you think this person is at exercising selfrestraint over desires, emotions, or impulses?" and "How capable do you think this person is at telling right from wrong?". Mental Experience items were "How capable do you think this person is at feeling afraid or fearful?" and "How capable do you think this person is at feeling physical or emotional pain?".

Moral Agency and Moral Patiency of a target woman were each assessed using two items, respectively (from Holland \& Haslam, 2013). Items were selected as the items with the highest factor loadings from Blake and colleagues' (2016) moral perceptions scale, used to assess perceptions of sexualized compared to non-sexualized women. Moral Agency items were "How much do you believe this person's achievements and actions are due to their thoughts and 
intentions, rather than luck and circumstances?" and "In general, how responsible do you think this person is for their actions in life?". Moral Patiency items were "How bad do you think you would feel if someone took advantage of this person?" and "How bad do you think you would feel if you manipulated this person?"

\section{Determination of final mental and moral dimensions}

Following our preregistered methods, we used Principal Components Analysis (PCA) to test whether indices of mental and moral dimensions of agency and patiency cluster separately or together. Our preregistration dictated that all four mental and moral dimension measures would be analyzed separately only if eigenvalues separating dimensions were greater than 1.0. Analysis revealed that the first two dimensions accounted for $83.2 \%$ of the overall variance captured within all mental and moral perceptions measures, but only the first dimension had an eigenvalue greater than 1. Principal Component 1 (eigenvalue $=2.71 ; 67.7 \%$ of variance) consisted of mental agency (rotated factor loading $=-.85)$, mental experience $(-.85)$, moral agency $(-.83)$ and moral patiency (-.75), forming an overall "humanness" dimension. Principal Component 2 (eigenvalue $=0.62 ; 15.5 \%$ of variance) separated variables mental agency $(.31)$ and moral agency (.39) from mental experience (-.17) and moral patiency (-.59), forming an agency/patiency measure. Eigenvalues separating agentic and patiency measures were less than 1 (Principal Component 2 eigenvalue $=0.62$; Component $3=0.37$; Component $4=0.30$ ).

Our pre-registration dictated that if eigenvalues separating dimensions were not greater than 1.0, we would create two overall indices. We based this decision on empirical and theoretical research indicating that mind and moral perceptions are dyadic (Gray et al., 2007; Gray \& Wegner, 2009; Waytz et al., 2010; Schein \& Gray, 2017), although some research suggests that, as our PCA shows, mind and moral attribution consist of only one overall dimension (Bastian et al., 2011a; 2011b; Khamitov et al., 2016). Following our preregistered methods, we combined indices to make two dimensions: one overall agency measure, consisting of the average of mental agency and moral agency items $(\alpha=.83)$, and one overall patiency measure, consisting of the average of mental experience and moral patiency items $(\alpha=.86$, see Table 3). We conducted additional exploratory analyses using the single humanness dimension determined by PCA. Results can be viewed in our Supplementary Materials. 
Table 3. Average ratings by male and female participants of women's overall agency and patiency

\begin{tabular}{|c|c|c|c|c|c|c|}
\hline & \multicolumn{2}{|c|}{ Men } & \multicolumn{2}{|c|}{ Women } & \multicolumn{2}{|c|}{ Overall } \\
\hline & $M$ & $S D$ & $M$ & $S D$ & $M$ & $S D$ \\
\hline Agency & 5.60 & 1.12 & 5.72 & 0.97 & 5.66 & 1.04 \\
\hline Patiency & 5.91 & 1.17 & 6.15 & 1.08 & 6.03 & 1.13 \\
\hline
\end{tabular}

Note: Agency and patiency were assessed using a 7-point Likert scale $(1=$ Low, $7=$ High $)$

\section{Perceived Amount of Makeup}

The perceived amount of makeup of each target woman was assessed using one item: "How much makeup do you think this person is wearing?" $(0=$ No makeup, $7=$ A lot of makeup; $M=3.35 S D=1.73$ ).

\section{Perceived Attractiveness of Target Woman}

The perceived attractiveness of each target woman was assessed a single item: "How attractive do you think this person is?" $(0=$ Not at all; $7=$ Extremely; $M=3.97, S D=1.60)$.

\section{Perceived Likeliness to Pursue Casual Sex of Target Woman}

The perceived likeliness of each target woman to pursue casual sex was assessed using two items adapted from the Revised Sociosexual Orientation Inventory (R-SOI; Penke \& Asendorpf, 2008; Stillman \& Maner, 2009). Items were "How likely do you think this person is to have a one night stand?" and "How likely do you think this person is to have (or have had) a lot of sexual partners?". $(0=$ Not at all; $7=$ Very; $M=3.66, S D=1.51, \alpha=.86)$.

\section{Individual Differences Measures}

Sociosexual orientation $(\alpha=.86)$ and mate value $(\alpha=.92)$ of participants were measured using the same measures as in Experiment 1.

\section{Data Analysis}

\section{General Linear Mixed Regression Analysis}

We conducted two General Linear Mixed regression models using the lme4 (Bates et al., 2015) and lmerTest (Kuznetsova et al., 2017) packages on agency and patiency indices to determine whether the amount of makeup a woman "wore" affected the agency (mental and 
moral) or patiency (mental and moral) she was attributed by others. Models included sex (of the participant), amount of makeup (of the target woman), scenario (condition group of target woman from Experiment 1), and their interactions. Participant SOI and mate value were included as covariates. Participant identity and target woman identity were included as random effects in the model.

\section{Mediation Analyses}

To test for differences in how perceptions of makeup influence male and female participants' attributions of mental capacity and moral status, we investigated whether the perception that a woman is attractive or is likely to pursue casual sex mediated the effect of the amount of makeup that a woman wears on agency and patiency attribution. We used secondstage moderated mediation bootstrapping analyses following methods reported by Hayes (2015) with 5,000 resamples using the lavaan package (Rosseel, 2012) on R 3.5.1 (R Core Team, 2019). We conducted two bootstrapped parallel moderated mediation models to determine whether the direct effects of makeup on perceptions of agency or patiency of target women was mediated by perceptions of the target women's attractiveness or likeliness to pursue casual sex. We included target women's attractiveness rating and average perceived SOI rating as predictors of the dependent variable (Figure 1; Figure 2). Sex of the participant was included as a moderator between the effect of perceived likeliness to pursue casual sex or perceived attractiveness on agency/patiency ratings. Mediation was considered significant if $95 \%$ bootstrapped confidence intervals (CI) for the indirect effect did not include zero (Preacher \& Hayes, 2004). Data, code and analyses can be found on the Open Science Framework (https://osf.io/xp9qc/?view only=90853c67d9cc48abb5d6895f08123e01).

\section{Results}

\section{Perceptions of women's makeup, agency and patiency}

Attributions of patiency, but not agency, differed significantly between male and female participants, with female participants attributing significantly more patiency to women than male participants (see Table 3 for average ratings). The perceived amount of makeup a woman wore, and the scenario the woman applied makeup for, did not significantly affect the amount of agency or patiency she was attributed. We did find a significant sex $\times$ perceived makeup interaction for agency attributions, indicating that the difference between female and male 
participants' agency attributions grew larger when they rated women wearing more makeup, compared to when they rated women wearing less makeup. Specifically, female participants tended to attribute women wearing more makeup slightly more agency, whereas male participants tended to attribute them slightly less agency (Male participants: $b=-.01, S E=.01$, $F_{1,2481}=2.94, p=.086$; Female participants: $\left.b=.02, S E=.01, F_{1,2556}=2.81, p=.094\right)$. We also found a significant sex $\times$ perceived amount of makeup interaction for patiency attributions, indicating that for female but not male participants, there was a significant negative relationship between ratings of patiency and increasing amounts of makeup (Male participants: $b=.004, S E$ $=.006$; Female participants: $b=-.01, S E=.005$ ). In other words, female participants' patiency ratings decreased as the amount of makeup women wore increased. Although female participants were more generous in their patiency attribution to women who wore little or no makeup compared with male participants, this difference was eventually eliminated as women wore moderate to high amounts of makeup. We found no additional interaction effects (see Table 4). 
Table 4. Results of pre-registered mixed linear regression models of agency and patiency ratings of women

\begin{tabular}{lccccccc}
\hline & \multicolumn{3}{c}{ Agency } & \multicolumn{3}{c}{ Patiency } \\
& d.f. & $F$ & $p$ & d.f. & $F$ & $p$ \\
\hline Sex & 1,1191 & 0.80 & .371 & 1,1067 & 14.32 & $<.001^{* * *}$ \\
Scenario & 3,554 & 0.36 & .784 & 3,611 & 0.99 & .398 \\
Perceived amount of makeup & 1,5034 & 0.01 & .917 & 1,4432 & 1.26 & .262 \\
Sex $\times$ Perceived amount of makeup & 1,7718 & 5.90 & $.015^{*}$ & 1,7630 & 5.66 & $.017^{*}$ \\
Sex $\times$ Scenario & 3,7476 & 0.51 & .674 & 3,7460 & 0.87 & .457 \\
Scenario $\times$ Perceived amount of makeup & 3,6298 & 0.72 & .539 & 3,5912 & 1.28 & .278 \\
Sex $\times$ Scenario $\times$ Perceived amount of & 3,7473 & 0.13 & .940 & 3,7457 & 1.56 & .197 \\
makeup & & & & & & \\
Covariates & & & & & & \\
$\quad$ SOI & & & & & & \\
$\quad$ Mate Value & 1,839 & 0.10 & .100 & 1,838 & 0.13 & .716 \\
\hline
\end{tabular}

Note: $* * * p<.001, * * p<.01, * p<.05,{ }^{\dagger} p<.10$.

\section{Indirect effects of perceived attractiveness and perceived sexual activity}

Agency mediation model results can be seen in Figure 1. Controlling for casual sex, attractiveness, and the casual sex $\times$ sex and attractiveness $\times$ sex interactions, perceived makeup had a significant direct effect on women's attributed agency (CI [-.04, -.02]). The effects of makeup on perceptions of a woman's agency were partially mediated by her perceived attractiveness and her perceived likeliness to have casual sex. Women wearing more makeup were viewed as significantly more attractive (CI [.24, .28]) which had a significant positive indirect effect on perceptions of their agency (CI $[.06, .11])$. Women wearing more makeup were also viewed as significantly more likely to pursue casual sex (CI [.33, .37]), which had a significant negative indirect effect on perceptions of their agency (CI [-.12, -.07]). The sex of the participant moderated the relationship between attractiveness and agency, with female participants attributing more attractive women slightly more agency than male participants (Female participants: $b=.04 \pm .003$, CI [.03, .04]; Male participants: $b=.02 \pm .003$, CI 
$[.02, .03])$, but did not moderate the relationship between likeliness to pursue casual sex and agency, indicating that male and female participants attributed similar agency to women based on their perceived sexual behavior.

Patiency mediation model results can be seen in Figure 2. Like the agency mediation model, when controlling for casual sex, attractiveness, and the casual sex $\times \operatorname{sex}$ and attractiveness $\times$ sex interactions, perceived makeup had a significant direct effect on women's attributed patiency (CI [-.11, -.08]), partially mediated by their perceived attractiveness and perceived likeliness to have casual sex. Women wearing more makeup were viewed as significantly more attractive (CI $[.24, .28])$, which had a significant positive indirect effect on perceptions of their patiency (CI $[.10, .14])$. Women wearing more makeup were also viewed as significantly more likely to pursue casual sex (CI $[.33, .37])$, which had a significant negative indirect effect on perceptions of their patiency (CI [-.06, -.01]), though, based on bootstrapped confidence intervals, a smaller indirect effect than on perceptions of agency. The sex of the participant moderated the relationship between attractiveness and patiency, with female participants attributing more attractive women slightly more patiency than male participants (Female participants: $\beta=.05, S E=.004, \mathrm{CI}[.04, .05]$; Male participants: $\beta=.03, S E=.004, \mathrm{CI}$ $[.02, .04])$. The sex of the participant also moderated the negative relationship between likeliness to pursue casual sex and patiency, with female participants attributing slightly less patiency than male participants (Female participants: $\beta=-.04, S E=.004$, CI [-.05, -.03]; Male participants: $\beta=$ $-.01, S E=.006$, CI [-.02, -.004]).

\section{Discussion}

Our mixed linear regression models showed significant sex $\times$ perceived amount of makeup interactions on agency and patiency attributions, but showed non-significant main effects of makeup on agency and patiency attributions. Our mediation models, however, showed direct effects of makeup on agency and patiency attributions as significant. Although the direct effects in the mediation model findings differ from the main effects in the linear regression findings, we caution that CIs of fixed effects estimates in the mediation model may be narrower than estimates within the multilevel regression model. This outcome is because additional random effects variables can increase uncertainty around fixed effects estimates (see Yarkoni, 2019). For this reason, estimates of the direct effects of makeup on agency or patiency 
attributions are best depicted in the mixed linear regression model results (because these model estimates are more conservative) and not the mediation models.

Taken together, we find that female but not male participants attribute less patiency, but also slightly more agency, to women who wear more makeup. Male participants' perceptions, in comparison, are only weakly influenced by a woman's heavier use of makeup, on average. However, male participants' overall perceptions of women's mental capacity and moral status were more negative than female participants' perceptions. These findings suggest that women view other women wearing more makeup less as patients (i.e., less capable of feelings and sensations) but slightly more as agents (i.e., more capable of thoughts and decision-making). This evidence does not support our fourth hypothesis that heavier makeup wearers would be attributed less patiency and less agency (H4). Instead, female participants' attributions of agency to women may increase because women are aware of other women's intentions to use makeup (Korichi et al., 2008; Mileva et al., 2016), but female participants' attributions of patiency may decrease because some women view attractive or sexualized same-sex competitors less positively (Agthe et al., 2011, 2016; Bernard et al., 2020; Delpriore et al., 2018; Puvia \& Vaes, 2013; Vaes et al., 2011; Waytz et al., 2010).

Research has found that judgements of women's agency are more negative, whereas judgements of women's patiency are more positive, when perceivers focus only on women's bodies, rather than the entire person (Gray et al., 2011). We find that when focusing on women's makeup-applied faces, however, female participants' judgements of women's patiency, but not their agency, are more negatively affected. Evidence shows that viewing a face - or even eyes placed on an inanimate object — can increase perceptions that the viewed person or non-human agent has a mind (Deska \& Hugenberg, 2017). Therefore, in comparison to body-focused female objectification whereby sexualized women can be perceived as lacking in competence, warmth, morality and humanness (Heflick et al. 2009; Heflick et al. 2011; Loughnan et al.; 2010), makeup may lead to a more specific view that heavy makeup wearers are lacking partially in mind, namely in patiency. Future replication is needed to corroborate these findings.

Both men's and women's positive mental and moral perceptions of women wearing more makeup are due to an association between wearing more makeup and being more attractive. Likewise, both men's and women's negative mental and moral perceptions of women wearing more makeup are due to an association between wearing more makeup and being more likely to 
have casual sex. Therefore, our results do not support that an association between makeup and attractiveness increases men's sexually objectifying perceptions of women (H5), but we do find evidence that an association between makeup and casual sex behavior increases women's and men's objectifying perceptions of other women (H6; Batres et al., 2018). Although men's overall objectification of women is greater than women's, interacting with other women more opposed to promiscuous behavior when wearing heavier makeup may also be costly for women (see Muggleton et al., 2018).

The results of Experiment 2 tell a consistent story: that the amount of makeup a woman wears can influence others' perceptions of her perceived ability to think, act intentionally, feel emotions, and receive moral treatment. Whether these perceptions were positive or negative depended upon the perceiver's associations between a woman's makeup, her attractiveness, and her likeliness to pursue casual sex. Substantial variation in the average perceptions of women in our experiment indicates that each woman's identity plays a considerable role in determining how these perceptions interact. Nonetheless, our results show that women can still be subjected to objectifying perceptions due to the amount of makeup they wear. 


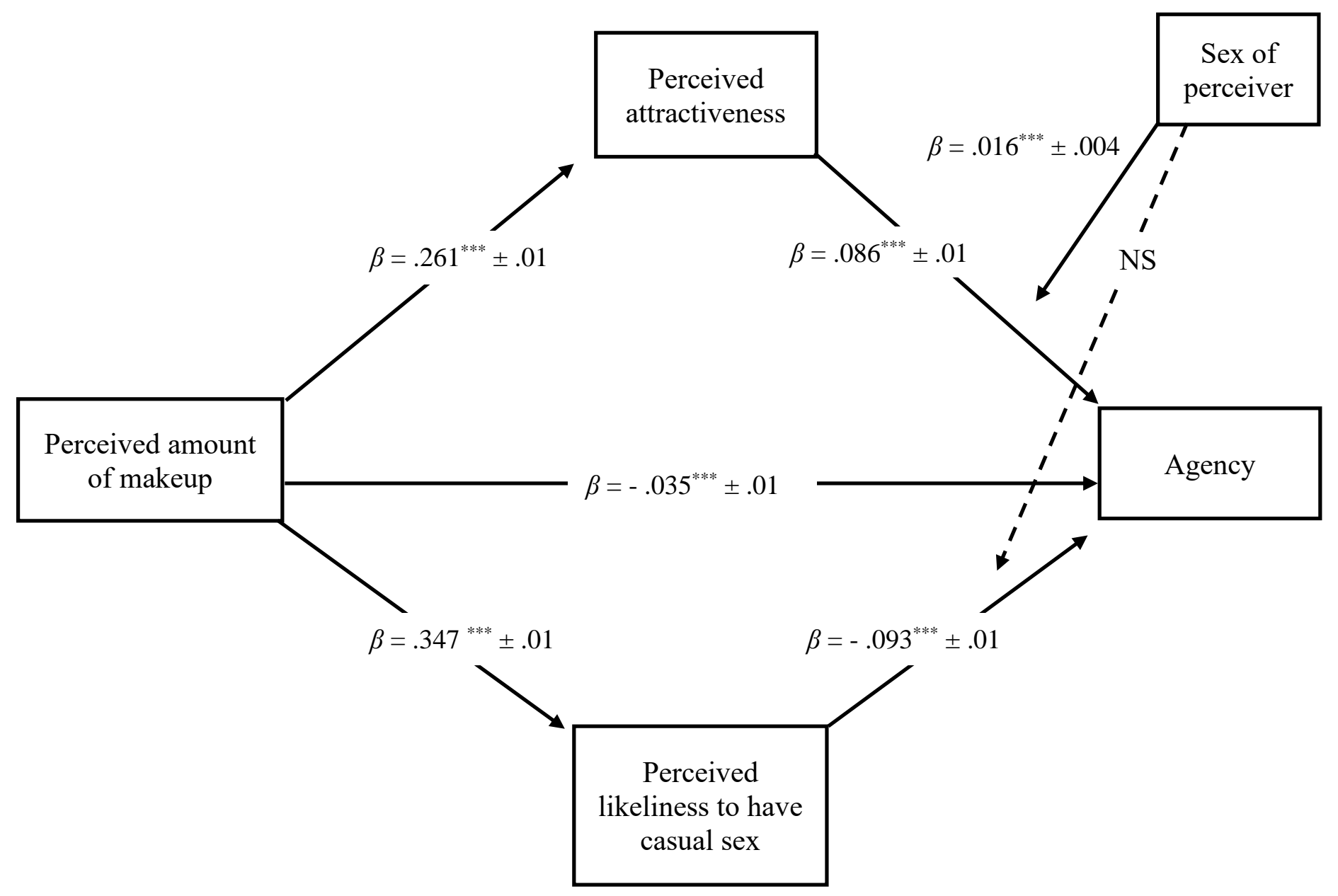

Figure 1. Mediation model for agency attribution. Dashed lines indicate non-significant paths. Parameter estimates are standardized. For moderator effects, beta values represent the difference in effects of women from men (men coded as baseline predictor). ${ }^{* * *} p<.001,{ }^{* *} p<.01,{ }^{*} p<.05,{ }^{\dagger} p<.10$. 


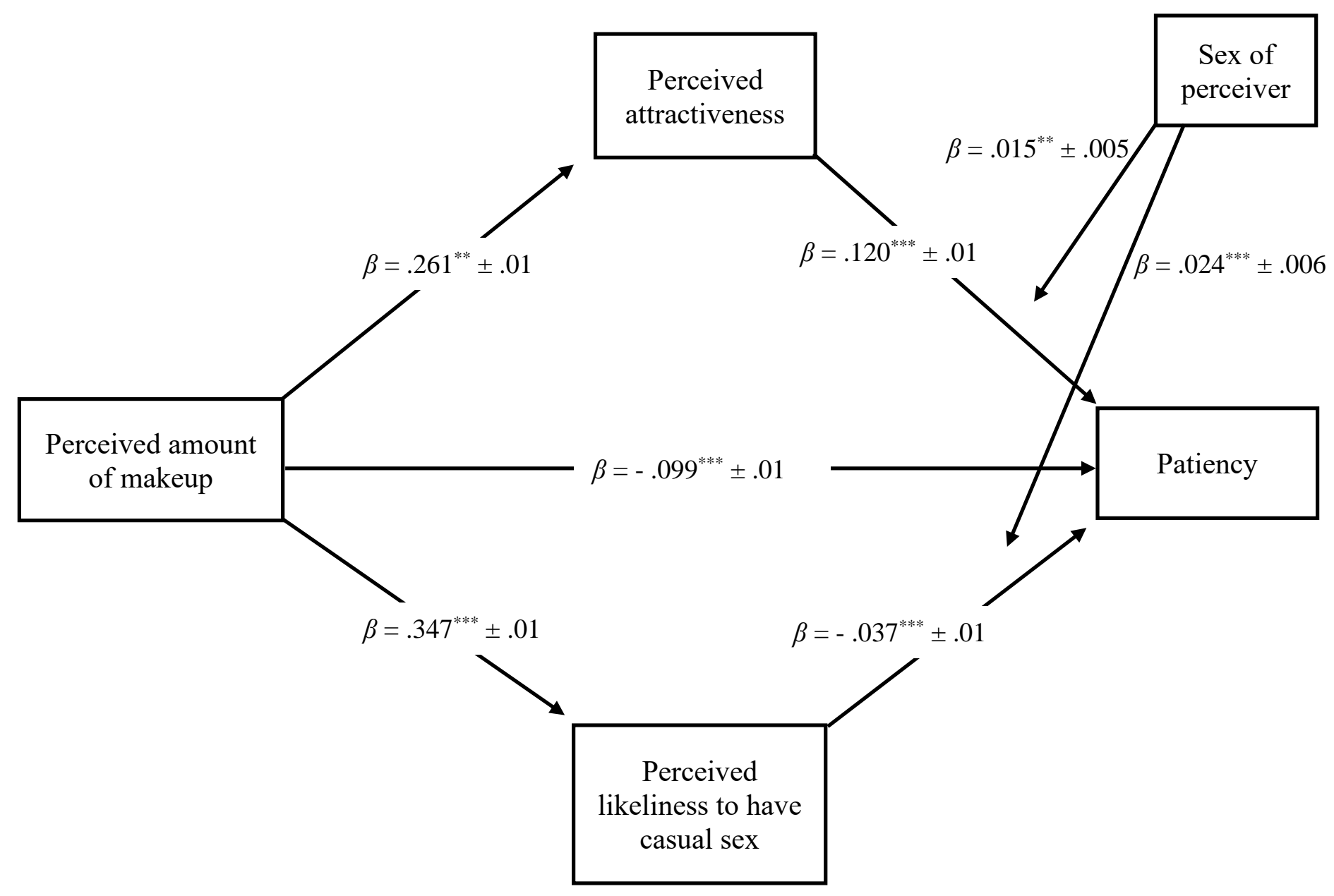

Figure 2. Mediation model for patiency attribution. Dashed lines indicate non-significant paths. Parameter estimates are standardized. For moderator effects, beta values represent the difference in effects of women from men (men coded as baseline predictor). ${ }^{* * *} p<.001,{ }^{* *} p<.01,{ }^{*} p<.05,{ }^{\dagger} p<.10$. 


\section{General Discussion}

Makeup can increase women's attractiveness and femininity at the possible expense of simultaneously increasing perceptions of unrestricted sexual behavior (Batres et al., 2018, Osborn, 1996; Mileva et al., 2016). Results from our first experiment suggest that the benefits of applying makeup on a woman's self-perceptions are limited, and that viewing herself wearing more makeup does not influence her self-perceived agency, humanness, competitiveness or resistance to a partner's jealousy. However, from our second experiment we find that objectifying judgements of a woman's mental capacity and moral status, especially by other women, are sensitive to the makeup she wears, in part due to an association that women who wear more makeup are more sexually active. Therefore, although makeup may not influence a women's self-perceptions, women who wear more makeup may still be viewed to have less mental and moral capacity by some people.

\section{Makeup and self-perceptions}

Our finding that makeup did not influence women's self-perceptions is inconsistent with evidence that wearing makeup can positively influence self-perceived body-image and attractiveness (Cash et al., 1989; Choi \& DeLong, 2019; Datta Gupta et al., 2016; Korichi et al., 2008). Our null findings also suggest that although sociometer theory predicts that a woman may confer psychological benefits from receiving positive responses about her appearance when desired (Leary \& Baumeister, 2000), the act of enhancing one's appearance in anticipation of a social event may not be sufficient to trigger these beneficial effects. One possible explanation for our null findings is that women may apply makeup regularly in order to meet gendered cultural expectations of femininity (Loegel et al., 2017, Henderson-King \& Brooks, 2009) rather than for agentic reasons, leaving women's true self-image unchanged. Our null findings may also demonstrate that applying makeup to an image rather than directly to one's face, and anticipating a hypothetical rather than an actual scenario, may have been an insufficient manipulation to stimulate responses associated with makeup application. Sensory aspects of makeup (e.g., touch, smell, sight) may be important to evoke positive and psychological stimulation (see Korichi et al., 2008; also see Batres et al., 2019). Further research using real makeup and real-life social interactions are necessary to fully discern how makeup affects self-perceived traits. 


\section{Makeup and other-perceptions}

Our findings support evidence that makeup increases a woman's attractiveness (Law Smith et al., 2006; Batres et al., 2018; Jones et al., 2015; Jones \& Kramer, 2016; Cash et al., 1989; Mileva et al., 2016), and that makeup's ability to do so can increase perceptions of her competence and warmth (Etcoff et al., 2011). Greater attractiveness did not, however, lower men's perceptions of women's mental capacity and moral status as expected if men sexually objectified women (Fredrickson \& Roberts, 1997; also see Calogero, 2004). Women may have been perceived more positively because makeup, by highlighting characteristically feminine facial features, may have increased perceptions that these women have other positive traits (Borau \& Bonnefon, 2019a; Dion, Bercheid \& Walster, 1972). Thus, makeup's ability to increase a woman's attractiveness can lead to positive effects on her attributed mental capacity and moral status.

We find wearing makeup can also lead to more negative perceptions of a women's mental capacity and moral status in ways much like that of sexualized appearances (Arnocky et al., 2019; Bernard et al. 2020; Bevens \& Loughnan, 2019; Loughnan et al., 2013; Vasquez et al., 2017). Theory suggests that body focus is an important driver of sexual objectification (Gervais et al., 2013; Fredrickson \& Roberts, 1997; also see Bartkey, 1990) and that viewing faces and eyes should reduce objectifying perceptions (for a review see Bernard et al., 2018b; Deska \& Hugenberg, 2017). However, our results show that even without body focus, stereotypes of sexual behavior can lead to objectifying results. Though effect sizes were modest across a large, ecologically valid sample of women's faces wearing a range of makeup, we find that negative stereotypes may still trigger some men and women to view women wearing heavier makeup more negatively. When choosing to wear makeup, women may face a trade-off between the benefits of attractiveness, and the consequences of negative stereotypes of women's sexuality (also see Little et al., 2014). Women, although culturally pressured to wear makeup, may therefore experience unintended consequences for choosing to do so.

\section{Limitations and future directions}

Our experimental results did not confirm our pre-registered hypotheses. Our analysis of the results in which we pre-registered an analysis plan did, however, reveal some significant effects, which we discuss and interpret with caution. These findings should be considered 
exploratory, rather than confirmatory. For example, we have discussed the negative effect of heavier makeup on women's perceptions of patiency but not agency as a possible new finding requiring future research even though our original hypothesis predicted negative effects on both patiency and agency. Our study's major findings of makeup's null effects on women's selfperceived traits, and makeup's effects on attributed agency and patiency towards women, also require future replication to corroborate. Should these effects replicate, makeup may influence people's dehumanizing judgements in a unique way compared to sexualized attire while providing little benefit to the wearer's own self-perceptions. Alternatively, if these effects are not replicable, one might conclude that makeup relates more closely to traditional objectifying perceptions of sexualized women, yet serve to benefit women's feelings of assertiveness or competitiveness in the mating market.

Some aspects of our experimental design limit the conclusions we can make from the current research. In Experiment 1 we did not specify the biological sex of the anticipated audience member(s) for any scenario (e.g., a male date, a female job interviewer, a majority female Instagram audience), nor did we specify whether the type of job a woman was interviewed for required many interactions with people (e.g., sales, modelling) or few interactions (e.g., backroom stock organizer). Our decision to not specify this information may have resulted in additional unintended variation in how women interpreted the appropriate makeup for each scenario. This limitation is compounded by not knowing the sexual orientation of our participants in Experiment 1, adding difficulty to interpretation of how each woman was affected by their allocated scenario, especially in the romantic date and Instagram post scenarios. Furthermore, using an Instagram post as a scenario of same-sex competition may not accurately match theoretical conditions of partner competition whereby women compete to secure partners and subsequently narrow the available pool of partners. An unclear relationship between the online Instagram environment and mating market dynamics limits our ability to interpret these findings.

Conclusions from Experiment 1 are also limited by our measures. Although auditory intentional binding tasks reliably indicate individual differences in agency (Imaizumi \& Tanno, 2019; Voss et al., 2010), within-subject experimental designs may provide more robust estimates of effects that are less susceptible to individual differences in attentional or sensory abilities. Additionally, our operationalization of attitudes towards same-sex individuals might not fully 
capture how makeup affects intrasexual competition because, without specifying, we could not know whether the women were assessed as a possible friend, competitor, or romantic partner. Our conclusions about participant's resistance to a partner's jealousy are similarly limited by the unknown sexual orientation of participants because we were unable to discern what motivated each woman's answers, and this measure may have been poorly suited to our sample of largely single participants. Another potentially important moderator of makeup effects on selfperceptions is whether women felt positively towards their makeup-applied appearance. The addition of this measure may have provided greater clarity about the reason for our null results and should be included in future studies on how makeup affects self-perceptions.

The effects of makeup on the perceptions of women detected in this study are subtle and possibly less important than other perceptions that men and women use to guide their attitudes and behaviors. For example, participants who rated faces were primarily Caucasian, but the faces they rated were mostly of women who identified as South East Asian or Chinese Asian. Although we statistically controlled for both participant and woman identity, it remains plausible that our findings are driven by ethnicity biases that we did not control for within our experimental design (e.g., Bain et al. 2009). It is also possible that our decision to not ask participants to remove any makeup they were already wearing prior to using the makeup app were insufficient to stimulate responses towards makeup. Although we hoped to avoid any psychological effects of forcing women to remove makeup from our experiment, this decision may have weakened the effects of the makeup manipulation even further by increasing between-subject differences in makeup application.

More recent public discourse has highlighted the importance of women's subjectivity and psychological well-being for women's political equality, social equality and empowerment through sexual identity (Gill, 2017; Gill \& Orgad, 2015). How cultural standards, including those regarding women's appearance, interact to define women's subjective experiences has been a topic of debate for decades, particularly within feminist literature (see Gill \& Orgad, 2018). A recent transition towards body-positivity among women, however, is shifting discussion of gender equity issues away from anti-sexualization and towards anti-sexism (Ringrose et al., 2013). The present research suggests that gendered stereotypes present hurdles that continue to limit women's ability to feel free to appear how they wish. The ability for women to dress attractively and feel confident in their appearance may have broader positive implications for 
women within society, and thus it is important that future research takes women's agency in their appearance choices into consideration. 


\section{References}

Agthe, M., Spörrle, M., \& Maner, J. K. (2011). Does being attractive always help? Positive and negative effects of attractiveness on social decision making. Personality \& Social Psychology Bulletin, 37(8), 1042-1054. https://doi.org/10.1177/0146167211410355

Agthe, M., Strobel, M., Spörrle, M., Pfundmair, M., \& Maner, J. K. (2016). On the Borders of Harmful and Helpful Beauty Biases. Evolutionary Psychology, 14(2), 147470491665396. https://doi.org/10.1177/1474704916653968

Arnocky, S., Ruddick, E. L., Proietti, V., Côté, T.-R., Ortiz, T. L., Hodson, G., \& Carré, J. M. (2019). Aggression Toward Sexualized Women Is Mediated by Decreased Perceptions of Humanness. Psychological Science, 956797619836106. https://doi.org/10.1177/0956797619836106

Aubrey, J. S. (2006). Effects of Sexually Objectifying Media on Self-Objectification and Body Surveillance in Undergraduates: Results of a 2-Year Panel Study. Journal of Communication, 56(2), 366-386. https://doi.org/10.1111/j.1460-2466.2006.00024.x

Bareket, O., Kahalon, R., Shnabel, N., \& Glick, P. (2018). The Madonna-Whore Dichotomy: Men Who Perceive Women's Nurturance and Sexuality as Mutually Exclusive Endorse Patriarchy and Show Lower Relationship Satisfaction. Sex Roles, 55. https://doi.org/10.1007/s11199-018-0895-7

Bastian, B., \& Haslam, N. (2011a). Experiencing Dehumanization: Cognitive and Emotional Effects of Everyday Dehumanization. Basic and Applied Social Psychology, 33(4), 295303. https://doi.org/10.1080/01973533.2011.614132

Bastian, B., Jetten, J., \& Radke, H. R.M. (2012). Cyber-dehumanization: Violent video game play diminishes our humanity. Journal of Experimental Social Psychology, 48(2), 486491. https://doi.org/10.1016/j.jesp.2011.10.009

Bastian, B., Laham, S. M., Wilson, S., Haslam, N., \& Koval, P. (2011b). Blaming, praising, and protecting our humanity: The implications of everyday dehumanization for judgments of moral status. The British Journal of Social Psychology, 50(3), 469-483. https://doi.org/10.1348/014466610X521383

Bates, D., Mächler, M., Bolker, B., \& Walker, S. (2015). Fitting Linear Mixed-Effects Models Using lme4. Journal of Statistical Software, 67(1). https://doi.org/10.18637/jss.v067.i01 
Batres, C., Kramer, S. S., DeAngelis, C. G., \& Russell, R. (2019). Examining the 'cosmetics placebo effect'. PLOS ONE, 14(1), e0210238. https://doi.org/10.1371/journal.pone.0210238

Batres, C., Russell, R., Simpson, J. A., Campbell, L., Hansen, A. M., \& Cronk, L. (2018). Evidence that makeup is a false signal of sociosexuality. Personality and Individual Differences, 122, 148-154. https://doi.org/10.1016/j.paid.2017.10.023

Berkowitz, L., \& Donnerstein, E. (1982). External validity is more than skin deep: Some answers to criticisms of laboratory experiments. American Psychologist, 37(3).

Bernard, P., Content, J., Servais, L., Wollast, R., \& Gervais, S. (2020). An Initial Test of the Cosmetics Dehumanization Hypothesis: Heavy Makeup Diminishes Attributions of Humanness-Related Traits to Women. Sex Roles, 1-13. https://doi.org/10.1007/s11199019-01115-y

Bernard, P., Gervais, S. J., Allen, J., Campomizzi, S., \& Klein, O. (2012). Integrating sexual objectification with object versus person recognition: The sexualized-body-inversion hypothesis. Psychological Science, 23(5), 469-471. https://doi.org/10.1177/0956797611434748

Bernard, P., Gervais, S. J., \& Klein, O. (2018a). Objectifying objectification: When and why people are cognitively reduced to their parts akin to objects. European Review of Social Psychology, 29(1), 82-121. https://doi.org/10.1080/10463283.2018.1471949

Bernard, P., Rizzo, T., Hoonhorst, I., Deliens, G., Gervais, S. J., Eberlen, J., . . Klein, O. (2018b). The Neural Correlates of Cognitive Objectification. Social Psychological and Personality Science, 9(5), 550-559. https://doi.org/10.1177/1948550617714582

Bevens, C. L., \& Loughnan, S. (2019). Insights into Men's Sexual Aggression Toward Women: Dehumanization and Objectification. Sex Roles. Advance online publication. https://doi.org/10.1007/s11199-019-01024-0

Biesterbos, J. W.H., Dudzina, T., Delmaar, C. J.E., Bakker, M. I., Russel, F. G.M., Goetz, N. von, . . Roeleveld, N. (2013). Usage patterns of personal care products: Important factors for exposure assessment. Food and Chemical Toxicology, 55, 8-17. https://doi.org/10.1016/j.fct.2012.11.014

Blake, K. R., \& Brooks, R. C. (2019a). Status anxiety mediates the positive relationship between income inequality and sexualization. Proceedings of the National Academy of Sciences of 
the United States of America, 116(50), 25029-25033. https://doi.org/10.1073/pnas.1909806116

Blake, K. R,, \& Brooks, R. C. (2019b). Income Inequality and Reproductive Competition: Implications for Consumption, Status-Seeking, and Women's Self-Sexualization. In J. Jetten \& K. Peters (Eds.), The Social Psychology of Inequality (Vol. 128, pp. 173-185). Cham: Springer. https://doi.org/10.1007/978-3-030-28856-3_11

Blake, K. R., Brooks, R., Arthur, L. C., \& Denson, T. F. (2020). In the context of romantic attraction, beautification can increase assertiveness in women. PloS One, 15(3), e0229162. https://doi.org/10.1371/journal.pone.0229162

Blake, K. R., Bastian, B., \& Denson, T. F. (2016). Perceptions of low agency and high sexual openness mediate the relationship between sexualization and sexual aggression. Aggressive Behavior, 42(5), 483-497. https://doi.org/10.1002/ab.21644

Blake, K. R., Bastian, B., Denson, T. F., Grosjean, P., \& Brooks, R. C. (2018). Income inequality not gender inequality positively covaries with female sexualization on social media. Proceedings of the National Academy of Sciences of the United States of America. Advance online publication. https://doi.org/10.1073/pnas.1717959115

Borau, S., \& Bonnefon, J.-F. (2019a). Gendered products act as the extended phenotype of human sexual dimorphism: They increase physical attractiveness and desirability. Journal of Business Research. Advance online publication. https://doi.org/10.1016/j.jbusres.2019.03.007

Borau, S., \& Bonnefon, J.-F. (2019b). The Imaginary Intrasexual Competition: Advertisements Featuring Provocative Female Models Trigger Women to Engage in Indirect Aggression. Journal of Business Ethics, 157(1), 45-63. https://doi.org/10.1007/s10551-017-3643-y

Buss, D. M., \& Schmitt, D. P. (1993). Sexual Strategies Theory: An evolutionary perspective on human mating. Psychological Review, 100(2), 204-232. https://doi.org/10.1037/0033295X.100.2.204

Buunk, A. P., \& Fisher, M. (2009). Individual differences in intrasexual competition. Journal of Evolutionary Psychology, 7(1), 37-48. https://doi.org/10.1556/JEP.7.2009.1.5

Calogero, R. M. (2004). A Test Of Objectification Theory: The Effect Of The Male Gaze On Appearance Concerns In College Women. Psychology of Women Quarterly, 28(1), 16-21. https://doi.org/10.1111/j.1471-6402.2004.00118.x 
Calogero, R. M., \& Jost, J. T. (2011). Self-subjugation among women: Exposure to sexist ideology, self-objectification, and the protective function of the need to avoid closure. Journal of Personality and Social Psychology, 100(2), 211-228. https://doi.org/10.1037/a0021864

Calogero, R. M., \& Pina, A. (2011). Body Guilt: Preliminary Evidence for a Further Subjective Experience of Self-Objectification. Psychology of Women Quarterly, 35(3), 428-440. https://doi.org/10.1177/0361684311408564

Cash, T., Dawson, K., Davis, P., Bowen, M., \& Galumbeck, C. (1989). Effects of Cosmetics Use on the Physical Attractiveness and Body Image of American College Women. The Journal of Social Psychology, 129(3), 349-355. https://doi.org/10.1080/00224545.1989.9712051

Cash, T. F., Rissi, J., \& Chapman, R. (1985). Not Just Another Pretty Face: Sex Roles, Locus of Control, and Cosmetics Use. Personality and Social Psychology Bulletin, 11(3), 246-257. https://doi.org/10.1177/0146167285113002

Chen, Z., Teng, F., \& Zhang, H. (2013). Sinful flesh: Sexual objectification threatens women's moral self. Journal of Experimental Social Psychology, 49(6), 1042-1048. https://doi.org/10.1016/j.jesp.2013.07.008

Choi, D., \& DeLong, M. (2019). Defining Female Self Sexualization for the Twenty-First Century. Sexuality \& Culture. Advance online publication. https://doi.org/10.1007/s12119-019-09617-3

Cikara, M., Eberhardt, J. L., \& Fiske, S. T. (2011). From agents to objects: Sexist attitudes and neural responses to sexualized targets. Journal of Cognitive Neuroscience, 23(3), 540551. https://doi.org/10.1162/jocn.2010.21497

Cogoni, C., Carnaghi, A., \& Silani, G. (2018). Reduced empathic responses for sexually objectified women: An fMRI investigation. Cortex, 99, 258-272. https://doi.org/10.1016/j.cortex.2017.11.020

Cox, C. L., \& Glick, W. H. (1986). Resume evaluations and cosmetics use: When more is not better. Sex Roles, 14(1-2), 51-58. https://doi.org/10.1007/BF00287847

Crawford, M., \& Popp, D. (2003). Sexual double standards: A review and methodological critique of two decades of research. Journal of Sex Research, 40(1), 13-26. https://doi.org/10.1080/00224490309552163 
Datta Gupta, N., Etcoff, N. L., \& Jaeger, M. M. (2016). Beauty in Mind: The Effects of Physical Attractiveness on Psychological Well-Being and Distress. Journal of Happiness Studies, 17(3), 1313-1325. https://doi.org/10.1007/s10902-015-9644-6

Davidson, M. M., Gervais, S. J., \& Sherd, L. W. (2015). The Ripple Effects of Stranger Harassment on Objectification of Self and Others. Psychology of Women Quarterly, 39(1), 53-66. https://doi.org/10.1177/0361684313514371

Davis, A. C., \& Arnocky, S. (2020). An Evolutionary Perspective on Appearance Enhancement Behavior. Archives of Sexual Behavior, 1-35. https://doi.org/10.1007/s10508-020-017454

Davis, K. C., George, W. H., Nagayama Hall, G. C., Parrott, D. J., Tharp, A. T., \& Stappenbeck, C. A. (2014). Studying Sexual Aggression: A Review of the Evolution and Validity of Laboratory Paradigms. Psychology of Violence, 4(4), 462-476. https://doi.org/10.1037/a0037662

Delpriore, D. J., Bradshaw, H. K., \& Hill, S. E. (2018). Appearance Enhancement Produces a Strategic Beautification Penalty Among Women. Evolutionary Behavioral Sciences. Advance online publication. https://doi.org/10.1037/ebs0000118

Deska, J. C., \& Hugenberg, K. (2017). The face-mind link: Why we see minds behind faces, and how others' minds change how we see their face. Social and Personality Psychology Compass, 11(12), e12361. https://doi.org/10.1111/spc3.12361

Diener, E., Wolsic, B., \& Fujita, F. (1995). Physical Attractiveness and Subjective Well-Being. Journal of Personality and Social Psychology, 69(1), 120-129. https://doi.org/10.1037/0022-3514.69.1.120

Dion, K., Berscheid, E., \& Walster, E. (1972). What is beautiful is good. Journal of Personality and Social Psychology, 24(3), 285-290. https://doi.org/10.1037/h0033731

Eastwick, P. W., Hunt, L. L., \& Neff, L. A. (2013). External Validity, Why Art Thou Externally Valid? Recent Studies of Attraction Provide Three Theoretical Answers. Social and Personality Psychology Compass, 7(5), 275-288. https://doi.org/10.1111/spc3.12026

Ebert, J. P., \& Wegner, D. M. (2010). Time warp: Authorship shapes the perceived timing of actions and events. Consciousness and Cognition, 19(1), 481-489. https://doi.org/10.1016/j.concog.2009.10.002 
Edlund, J. E., \& Sagarin, B. J. (2014). The Mate Value Scale. Personality and Individual Differences, 64, 72-77. https://doi.org/10.1016/j.paid.2014.02.005

Etcoff, N. L., Stock, S., Haley, L. E., Vickery, S. A., \& House, D. M. (2011). Cosmetics as a feature of the extended human phenotype: Modulation of the perception of biologically important facial signals. PloS One, 6(10), e25656. https://doi.org/10.1371/journal.pone.0025656

Fredrickson, B. L., \& Roberts, T.-A. (1997). Objectification Theory: Toward Understanding Women's Lived Experiences and Mental Health Risks. Psychology of Women Quarterly, 21(2), 173-206. https://doi.org/10.1111/j.1471-6402.1997.tb00108.x

Fredrickson, B. L., Roberts, T.-A., Noll, S. M., Quinn, D. M., \& Twenge, J. M. (1998). That swimsuit becomes you: Sex differences in self-objectification, restrained eating, and math performance. Journal of Personality and Social Psychology, 75(1), 269-284. https://doi.org/10.1037/0022-3514.75.1.269

Fugère, M. A., Cousins, A. J., \& MacLaren, S. A. (2015). (Mis)matching in physical attractiveness and women's resistance to mate guarding. Personality and Individual Differences, 87, 190-195. https://doi.org/10.1016/j.paid.2015.07.048

Galesic, M., \& Bosnjak, M. (2009). Effects of Questionnaire Length on Participation and Indicators of Response Quality in a Web Survey. Public Opinion Quarterly, 73(2), 349360. https://doi.org/10.1093/poq/nfp031

Gebauer, J. E., Sedikides, C., Verplanken, B., \& Maio, G. R. (2012). Communal narcissism. Journal of Personality and Social Psychology, 103(5), 854-878. https://doi.org/10.1037/a0029629

Gervais, S. J., Holland, A. M., \& Dodd, M. D. (2013). My Eyes Are Up Here: The Nature of the Objectifying Gaze Toward Women. Sex Roles, 69(11-12), 557-570. https://doi.org/10.1007/s11199-013-0316-X

Gill, R. (2017). The affective, cultural and psychic life of postfeminism: A postfeminist sensibility 10 years on. European Journal of Cultural Studies, 20(6), 606-626. https://doi.org/10.1177/1367549417733003

Gill, R., \& Orgad, S. (2015). The Confidence Cult(ure). Australian Feminist Studies, 30(86), 324-344. https://doi.org/10.1080/08164649.2016.1148001 
Gill, R., \& Orgad, S. (2018). The shifting terrain of sex and power: From the 'sexualization of culture' to \# MeToo. Sexualities, 21(8), 1313-1324. https://doi.org/10.1177/1363460718794647

Goodwin, R., Marshall, T., Fülöp, M., Adonu, J., Spiewak, S., Neto, F., \& Plaza, S. H. (2012). Mate Value and Self-Esteem: Evidence from Eight Cultural Groups. PLOS ONE, 7(4), e36106. https://doi.org/10.1371/journal.pone.0036106

Graff, K., Murnen, S. K., \& Smolak, L. (2012). Too Sexualized to be Taken Seriously? Perceptions of a Girl in Childlike vs. Sexualizing Clothing. Sex Roles, 66(11-12), 764775. https://doi.org/10.1007/s11199-012-0145-3

Gray, H. M., Gray, K., \& Wegner, D. M. (2007). Dimensions of mind perception. Science (New York, N.Y.), 315(5812), 619. https://doi.org/10.1126/science.1134475

Gray, K., Knobe, J., Sheskin, M., Bloom, P., \& Barrett, L. F. (2011). More than a body: Mind perception and the nature of objectification. Journal of Personality and Social Psychology, 101(6), 1207-1220. https://doi.org/10.1037/a0025883

Gray, K., \& Wegner, D. M. (2009). Moral typecasting: Divergent perceptions of moral agents and moral patients. Journal of Personality and Social Psychology, 96(3), 505-520. https://doi.org/10.1037/a0013748

Gray, K., Young, L., \& Waytz, A. (2012). Mind Perception Is the Essence of Morality. Psychological Inquiry, 23(2), 101-124. https://doi.org/10.1080/1047840X.2012.651387

Gurung, R. A. R., \& Chrouser, C. J. (2007). Predicting Objectification: Do Provocative Clothing and Observer Characteristics Matter? Sex Roles, 57(1-2), 91-99. https://doi.org/10.1007/s11199-007-9219-z

Haggard, P., Clark, S., \& Kalogeras, J. (2002). Voluntary action and conscious awareness. Nature Neuroscience, 5(4), 382-385. https://doi.org/10.1038/nn827

Haslam, N. (2006). Dehumanization: An integrative review. Personality and Social Psychology Review, 10(3), 252-264. https://doi.org/10.1207/s15327957pspr1003_4

Haslam, N., Bain, P., Douge, L., Lee, M., \& Bastian, B. (2005). More human than you: Attributing humanness to self and others. Journal of Personality and Social Psychology, 89(6), 937-950. https://doi.org/10.1037/0022-3514.89.6.937

Haslam, N., \& Loughnan, S. (2014). Dehumanization and infrahumanization. Annual Review of Psychology, 65, 399-423. https://doi.org/10.1146/annurev-psych-010213-115045 
Haslam, N., \& Stratemeyer, M. (2016). Recent research on dehumanization. Current Opinion in Psychology, 11, 25-29. https://doi.org/10.1016/j.copsyc.2016.03.009

Hayes, A. F. (2015). An Index and Test of Linear Moderated Mediation. Multivariate Behavioral Research, 50(1), 1-22. https://doi.org/10.1080/00273171.2014.962683

Heflick, N. A., \& Goldenberg, J. L. (2009). Objectifying Sarah Palin: Evidence that objectification causes women to be perceived as less competent and less fully human. Journal of Experimental Social Psychology, 45(3), 598-601. https://doi.org/10.1016/j.jesp.2009.02.008

Heflick, N. A., Goldenberg, J. L., Cooper, D. P., \& Puvia, E. (2011). From women to objects: Appearance focus, target gender, and perceptions of warmth, morality and competence. Journal of Experimental Social Psychology, 47(3), 572-581. https://doi.org/10.1016/j.jesp.2010.12.020

Henderson-King, D., \& Brooks, K. d. (2009). Materialism, Sociocultural Appearance Messages, and Paternal Attitudes Predict College Women's Attitudes About Cosmetic Surgery. Psychology of Women Quarterly, 33(1), 133-142. https://doi.org/10.1111/j.14716402.2008.01480.x

Hendrickse, J., Arpan, L. M., Clayton, R. B., \& Ridgway, J. L. (2017). Instagram and college women's body image: Investigating the roles of appearance-related comparisons and intrasexual competition. Computers in Human Behavior, 74, 92-100. https://doi.org/10.1016/j.chb.2017.04.027

Herzog, A. R., \& Bachman, J. G. (1981). Effects of Questionnaire Length on Response Quality. Public Opinion Quarterly, 45(4), 549-559. https://doi.org/10.1086/268687

Hill, S. E., Rodeheffer, C. D., Griskevicius, V., Durante, K., \& White, A. E. (2012). Boosting beauty in an economic decline: Mating, spending, and the lipstick effect. Journal of Personality and Social Psychology, 103(2), 275-291. https://doi.org/10.1037/a0028657

Holland, E., \& Haslam, N. (2013). Worth the Weight: The Objectification of Overweight Versus Thin Targets. Psychology of Women Quarterly, 37(4), 462-468. https://doi.org/10.1177/0361684312474800

Holland, E., \& Haslam, N. (2016). Cute Little Things: The Objectification of Prepubescent Girls. Psychology of Women Quarterly, 40(1), 108-119. https://doi.org/10.1177/0361684315602887 
Holland, E., Koval, P., Stratemeyer, M., Thomson, F., \& Haslam, N. (2017). Sexual objectification in women's daily lives: A smartphone ecological momentary assessment study. The British Journal of Social Psychology, 56(2), 314-333. https://doi.org/10.1111/bjso.12152

Hopstaken, J. F., van der Linden, D., Bakker, A. B., \& Kompier, M. A. J. (2015). A multifaceted investigation of the link between mental fatigue and task disengagement. Psychophysiology, 52(3), 305-315. https://doi.org/10.1111/psyp.12339

Jackson, L. A., Hunter, J. E., \& Hodge, C. N. (1995). Physical Attractiveness and Intellectual Competence: A Meta-Analytic Review. Social Psychology Quarterly, 58(2), 108. https://doi.org/10.2307/2787149

James, E. A., Jenkins, S., \& Watkins, C. D. (2018). Negative Effects of Makeup Use on Perceptions of Leadership Ability Across Two Ethnicities. Perception, 301006618763263. https://doi.org/10.1177/0301006618763263

Jones, A. L., \& Kramer, R. S. S. (2016). Facial Cosmetics and Attractiveness: Comparing the Effect Sizes of Professionally-Applied Cosmetics and Identity. PloS One, 11(10), e0164218. https://doi.org/10.1371/journal.pone.0164218

Jones, A. L., Russell, R., \& Ward, R. (2015). Cosmetics Alter Biologically-Based Factors of Beauty: Evidence from Facial Contrast. Evolutionary Psychology, 13(1), 147470491501300. https://doi.org/10.1177/147470491501300113

Klatt, J., Eimler, S. C., \& Krämer, N. C. (2016). Makeup your mind: The impact of styling on perceived competence and warmth of female leaders. The Journal of Social Psychology, 156(5), 483-497. https://doi.org/10.1080/00224545.2015.1129303

Ko, A., \& Suh, E. M. (2019). Does physical attractiveness buy happiness? Women's mating motivation and happiness. Motivation and Emotion, 43(1), 1-11. https://doi.org/10.1007/s11031-018-9717-z

Korichi, R., Pelle-de-Queral, D., Gazano, G., \& Aubert, A. (2008). Why women use makeup: Implication of psychological traits in makeup functions. Journal of Cosmetic Science, 59(2), 127-137.

Kuznetsova, A., Brockhoff, P. B., \& Christensen, R. H. B. (2017). 1merTest Package: Tests in Linear Mixed Effects Models. Journal of Statistical Software, 82(13). https://doi.org/10.18637/jss.v082.i13 
Lavrakas, P. J. (Ed.) (2008). Encyclopedia of survey research methods. Los Angeles, London: SAGE. https://doi.org/10.4135/9781412963947

Law Smith, M. J., Perrett, D. I., Jones, B. C., Cornwell, R. E., Moore, F. R., Feinberg, D. R., . . . Hillier, S. G. (2006). Facial appearance is a cue to oestrogen levels in women. Proceedings. Biological Sciences, 273(1583), 135-140. https://doi.org/10.1098/rspb.2005.3296

Leary, M. R., \& Baumeister, R. F. (2000). The nature and function of self-esteem: Sociometer theory. In Advances in Experimental Social Psychology (Vol. 32, pp. 1-62). Academic Press. https://doi.org/10.1016/S0065-2601(00)80003-9

Little, A. C., Jones, B. C., \& DeBruine, L. M. (2011). Facial attractiveness: Evolutionary based research. Philosophical Transactions of the Royal Society of London. Series B, Biological Sciences, 366(1571), 1638-1659. https://doi.org/10.1098/rstb.2010.0404

Loegel, A., Courrèges, S., Morizot, F., \& Fontayne, P. (2017). Makeup, an essential tool to manage social expectations surrounding femininity? Movement Sport Sciences, 96(2), 19-25. https://doi.org/10.1051/sm/2017007

L'Oreal. (2018). 2018 Registration Document. Retrieved from https://www.lorealfinance.com/eng/registration-document

Loughnan, S., Baldissarri, C., Spaccatini, F., \& Elder, L. (2017). Internalizing objectification: Objectified individuals see themselves as less warm, competent, moral, and human. The British Journal of Social Psychology, 56(2), 217-232. https://doi.org/10.1111/bjso.12188

Loughnan, S., Fernandez-Campos, S., Vaes, J., Anjum, G., Aziz, M., Harada, C., . . Tsuchiya, K. (2015). Exploring the role of culture in sexual objectification: A seven nations study. Revue internationale de psychologie sociale, Tome 28(1), 125-152. Retrieved from https://www.cairn.info/load_pdf.php?ID_ARTICLE=RIPSO_281_0125\&download=1

Loughnan, S., Haslam, N., Murnane, T., Vaes, J., Reynolds, C., \& Suitner, C. (2010). Objectification leads to depersonalization: The denial of mind and moral concern to objectified others. European Journal of Social Psychology, 40, 709-717. https://doi.org/10.1002/ejsp.755

Loughnan, S., Pina, A., Vasquez, E. A., \& Puvia, E. (2013). Sexual Objectification Increases Rape Victim Blame and Decreases Perceived Suffering. Psychology of Women Quarterly, 37(4), 455-461. https://doi.org/10.1177/0361684313485718 
Maestripieri, D., Henry, A., \& Nickels, N. (2017). Explaining financial and prosocial biases in favor of attractive people: Interdisciplinary perspectives from economics, social psychology, and evolutionary psychology. The Behavioral and Brain Sciences, 40, e19. https://doi.org/10.1017/S0140525X16000340

Meltzer, A. L. (2019). Women Can Benefit From Sexual and Physical Valuation in the Context of a Romantic Relationship. Personality \& Social Psychology Bulletin, 146167219854443. https://doi.org/10.1177/0146167219854443

Mileva, V. R., Jones, A. L., Russell, R., \& Little, A. C. (2016). Sex Differences in the Perceived Dominance and Prestige of Women With and Without Cosmetics. Perception, 45(10), 1166-1183. https://doi.org/10.1177/0301006616652053

Mitchell, G. (2012). Revisiting Truth or Triviality: The External Validity of Research in the Psychological Laboratory. Perspectives on Psychological Science, 7(2), 109-117. https://doi.org/10.1177/1745691611432343

Moore, J., \& Haggard, P. (2008). Awareness of action: Inference and prediction. Consciousness and Cognition, 17(1), 136-144. https://doi.org/10.1016/j.concog.2006.12.004

Moore, J. W., \& Obhi, S. S. (2012). Intentional binding and the sense of agency: A review. Consciousness and Cognition, 21(1), 546-561. https://doi.org/10.1016/j.concog.2011.12.002

Moradi, B., \& Huang, Y.-P. (2008). Objectification Theory and Psychology of Women: A Decade of Advances and Future Directions. Psychology of Women Quarterly, 32(4), 377-398. https://doi.org/10.1111/j.1471-6402.2008.00452.x

Morris, K. L., Goldenberg, J., \& Boyd, P. (2018). Women as Animals, Women as Objects: Evidence for Two Forms of Objectification. Personality \& Social Psychology Bulletin, 44(9), 1302-1314. https://doi.org/10.1177/0146167218765739

Muggleton, N. K., Tarran, S. R., \& Fincher, C. L. (2018). Who punishes promiscuous women? Both women and men, but only women inflict costly punishment. Evolution and Human Behavior. Advance online publication. https://doi.org/10.1016/j.evolhumbehav.2018.12.003

Nash, R., Fieldman, G., Hussey, T., Lévêque, J. L., \& Pineau, P. (2006). Cosmetics: They Influence More Than Caucasian Female Facial Attractiveness. Journal of Applied Social Psychology, 36(2), 493-504. https://doi.org/10.1111/j.0021-9029.2006.00016.x 
Netchaeva, E., \& Rees, M. (2016). Strategically Stunning: The Professional Motivations Behind the Lipstick Effect. Psychological Science, 27(8), 1157-1168. https://doi.org/10.1177/0956797616654677

Nussbaum, M. C. (1999). Sex and social justice: Oxford University Press.

Osborn, D. R. (1996). Beauty is as Beauty Does? Makeup and Posture Effects on Physical Attractiveness Judgments. Journal of Applied Social Psychology, 26(1), 31-51. https://doi.org/10.1111/j.1559-1816.1996.tb01837.x

Pacilli, M. G., Giovannelli, I., Spaccatini, F., Vaes, J., \& Barbaranelli, C. (2018). Elective Abortion Predicts the Dehumanization of Women and Men Through the Mediation of Moral Outrage. Social Psychology, 49(5), 287-302. https://doi.org/10.1027/1864$9335 / \mathrm{a} 000351$

Park, G.-H., Nam, C., Hong, S., Park, B., Kim, H., Lee, T., . . Kim, M. H. (2018). Socioeconomic factors influencing cosmetic usage patterns. Journal of Exposure Science and Environmental Epidemiology, 28(3), 242. https://doi.org/10.1038/jes.2017.20

Penke, L., \& Asendorpf, J. B. (2008). Beyond global sociosexual orientations: A more differentiated look at sociosexuality and its effects on courtship and romantic relationships. Journal of Personality and Social Psychology, 95(5), 1113-1135. https://doi.org/10.1037/0022-3514.95.5.1113

Penke, L., \& Denissen, J. J.A. (2008). Sex differences and lifestyle-dependent shifts in the attunement of self-esteem to self-perceived mate value: Hints to an adaptive mechanism? Journal of Research in Personality, 42(4), 1123-1129. https://doi.org/10.1016/j.jrp.2008.02.003

Preacher, K. J., \& Hayes, A. F. (2004). SPSS and SAS procedures for estimating indirect effects in simple mediation models. Behavior Research Methods, Instruments, \& Computers, 36(4), 717-731. https://doi.org/10.3758/BF03206553

Putz, Á., Kocsor, F., \& Bereczkei, T. (2018). Beauty stereotypes affect the generalization of behavioral traits associated with previously seen faces. Personality and Individual Differences, 131, 7-14. https://doi.org/10.1016/j.paid.2018.04.011

Puvia, E., \& Vaes, J. (2013). Being a Body: Women's Appearance Related Self-Views and their Dehumanization of Sexually Objectified Female Targets. Sex Roles, 68(7-8), 484-495. https://doi.org/10.1007/s11199-012-0255-y 
Puvia, E., \& Vaes, J. (2015). Promoters versus victims of objectification: Why women dehumanize sexually objectified female targets. Revue internationale de psychologie sociale, 28(1), 63-93.

R Development Core Team (2019). $R$ : A language and environment for statistical computing: $R$ Foundation for Statistical Computing. Vienna, Austria. Retrieved from http://www.Rproject.org

Reiss, I. L. (1967). The social context of premarital sexual permissiveness.

Ringrose, J., Harvey, L., Gill, R., \& Livingstone, S. (2013). Teen girls, sexual double standards and 'sexting': Gendered value in digital image exchange. Feminist Theory, 14(3), 305323. https://doi.org/10.1177/1464700113499853

Rosseel, Y. (2012). lavaan: An R Package for Structural Equation Modeling. Journal of Statistical Software, 48(2). https://doi.org/10.18637/jss.v048.i02

Rudman, L. A., \& Mescher, K. (2012). Of animals and objects: Men's implicit dehumanization of women and likelihood of sexual aggression. Personality \& Social Psychology Bulletin, 38(6), 734-746. https://doi.org/10.1177/0146167212436401

Russell, R. (2010). Why Cosmetics Work. In R. B. Adams (Ed.), Oxford series in visual cognition: Vol. 7. The science of social vision (pp. 186-203). New York, Oxford: Oxford University Press. https://doi.org/10.1093/acprof:oso/9780195333176.003.0011

Saguy, T., Quinn, D. M., Dovidio, J. F., \& Pratto, F. (2010). Interacting like a body: Objectification can lead women to narrow their presence in social interactions. Psychological Science, 21(2), 178-182. https://doi.org/10.1177/0956797609357751

Sanchez, D. T., \& Broccoli, T. L. (2008). The Romance of Self-objectification: Does Priming Romantic Relationships Induce States of Self-objectification Among Women? Sex Roles, 59(7-8), 545-554. https://doi.org/10.1007/s11199-008-9451-1

Schein, C., \& Gray, K. (2017). The Theory of Dyadic Morality: Reinventing Moral Judgment by Redefining Harm. Personality and Social Psychology Review, 1088868317698288. https://doi.org/10.1177/1088868317698288

Schroeder, J., Waytz, A., \& Epley, N. (2017). Endorsing help for others that you oppose for yourself: Mind perception alters the perceived effectiveness of paternalism. Journal of Experimental Psychology. General, 146(8), 1106-1125. https://doi.org/10.1037/xge0000320 
Smith, F. G., DeBruine, L. M., Jones, B. C., Krupp, D. B., Welling, L. L.M., \& Conway, C. A. (2009). Attractiveness qualifies the effect of observation on trusting behavior in an economic game. Evolution and Human Behavior, 30(6), 393-397. https://doi.org/10.1016/j.evolhumbehav.2009.06.003

Statista. (2017). Frequency of makeup use among consumers in the United States as of May 2017. Retrieved from https://www.statista.com/statistics/712691/makeup-frequency-ofuse/

Statista. (2019a). Most-followed beauty and fashion influences on Instagram worldwide as of March 2019. Retrieved from https://www.statista.com/statistics/788498/most-followersinstagram-fashion-global/

Statista. (2019b). Most popular YouTube beauty and style channels as of April 2019, ranked by number of subscribers (in millions). Retrieved from https://www.statista.com/statistics/627448/most-popular-youtube-beauty-channelsranked-by-subscribers/

Stillman, T. F., \& Maner, J. K. (2009). A sharp eye for her SOI: Perception and misperception of female sociosexuality at zero acquaintance. Evolution and Human Behavior, 30(2), 124130. https://doi.org/10.1016/j.evolhumbehav.2008.09.005

Strelan, P., \& Hargreaves, D. (2005). Women Who Objectify Other Women: The Vicious Circle of Objectification? Sex Roles, 52(9-10), 707-712. https://doi.org/10.1007/s11199-0053737-3

Tyler, J. M., Calogero, R. M., \& Adams, K. E. (2017). Perpetuation of sexual objectification: The role of resource depletion. British Journal of Social Psychology, 56(2), 334-353. https://doi.org/10.1111/bjso.12157

Vaes, J., Cristoforetti, G., Ruzzante, D., Cogoni, C., \& Mazza, V. (2019). Assessing neural responses towards objectified human targets and objects to identify processes of sexual objectification that go beyond the metaphor. Scientific Reports, 9(1), 6699. https://doi.org/10.1038/s41598-019-42928-X

Vaes, J., Paladino, P., \& Puvia, E. (2011). Are sexualized women complete human beings? Why men and women dehumanize sexually objectified women. European Journal of Social Psychology, 41(6), 774-785. https://doi.org/10.1002/ejsp.824 
Vasquez, E. A., Ball, L., Loughnan, S., \& Pina, A. (2017). The object of my aggression: Sexual objectification increases physical aggression toward women. Aggressive Behavior. Advance online publication. https://doi.org/10.1002/ab.21719

Von Baeyer, C. L., Sherk, D. L., \& Zanna, M. P. (1981). Impression Management in the Job Interview. Personality and Social Psychology Bulletin, 7(1), 45-51. https://doi.org/10.1177/014616728171008

Voss, M., Moore, J., Hauser, M., Gallinat, J., Heinz, A., \& Haggard, P. (2010). Altered awareness of action in schizophrenia: A specific deficit in predicting action consequences. Brain : A Journal of Neurology, 133(10), 3104-3112. https://doi.org/10.1093/brain/awq152

Wagstaff, D. (2018). Comparing Mating Motivations, Social Processes, and Personality as Predictors of Women's Cosmetics Use. Evolutionary Behavioral Sciences, 12(4), 367380. https://doi.org/10.1037/ebs0000119

Watkins, C. D., Quist, M. C., Smith, F. G., DeBruine, L. M., \& Jones, B. C. (2012). Individual differences in women's perceptions of other women's dominance. European Journal of Personality, 26(1), 79-86. https://doi.org/10.1002/per.837

Waytz, A., Gray, K., Epley, N., \& Wegner, D. M. (2010). Causes and consequences of mind perception. Trends in Cognitive Sciences, 14(8), 383-388. https://doi.org/10.1016/j.tics.2010.05.006

Weeden, J., Cohen, A. B., \& Kenrick, D. T. (2008). Religious Attendance as Reproductive Support. Evolution and Human Behavior, 29(5), 327-334. https://doi.org/10.1016/j.evolhumbehav.2008.03.004

Weeden, J., \& Kurzban, R. (2013). What predicts religiosity? A multinational analysis of reproductive and cooperative morals. Evolution and Human Behavior, 34(6), 440-445. https://doi.org/10.1016/j.evolhumbehav.2013.08.006

Yarkoni, T. (2019, November 22). The Generalizability Crisis. https://doi.org/10.31234/osf.io/jqw35

Zion Market Research. (2017). Cosmetic Products Market by Product (Skin care products, Haircare products, Color osmetics, Fragrances, Personal care products, and Oral care products), by Form (solutions, Creams, Lotions, Ointments, Suspensions, Tablets, Powders, Gels, Sticks, and Aerosols), by Application (Lips, Eyes, Eyebros, Nails, and Face), by Distribution Channel (Online, Beauty salons, Specialty stores, Direct selling, 
Departmental stores, Pharmacy, and Supermarkets), by Region (North America, Europe, Asia Pacific, Latin America, and the Middle East \& Africa) - Global Industry Perspective, Comprehensive Analysis and Forecast, 2017 - 2024. Retrieved from https://www.zionmarketresearch.com/report/cosmetic-products-market 